\title{
Review Article \\ Shape-Controlled Metal Nanoparticles and Their Assemblies with Optical Functionalities
}

\author{
Go Kawamura, ${ }^{1}$ Masayuki Nogami, ${ }^{2}$ and Atsunori Matsuda ${ }^{1}$ \\ ${ }^{1}$ Department of Electrical and Electronic Information Engineering, Toyohashi University of Technology, 1-1 Hibarigaoka, \\ Tempaku-cho, Toyohashi 441-8580, Japan \\ ${ }^{2}$ Department of Frontier Materials, Nagoya Institute of Technology, Gokiso, Showa-ku, Nagoya 466-8555, Japan
}

Correspondence should be addressed to Go Kawamura; gokawamura@ee.tut.ac.jp

Received 26 September 2012; Revised 4 December 2012; Accepted 4 December 2012

Academic Editor: Yong Yang

Copyright (C) 2013 Go Kawamura et al. This is an open access article distributed under the Creative Commons Attribution License, which permits unrestricted use, distribution, and reproduction in any medium, provided the original work is properly cited.

\begin{abstract}
Metal nanoparticles (NPs) possess excellent optical, optoelectronic, and optochemical properties based on their surface plasmon resonance. However, for practical use, the morphology and assembly of metal NPs need to be controlled. Here, we review facile control methods including seed-mediated growth accompanied with a comproportionation reaction of seeds to control their morphology and assembly. Several synthetic conditions have been modified to precisely control the morphology of metal NPs. Functionalized mesoporous oxides have also been used as hard templates to align metal nanorods and control their dimensions. The high performance of such metal nanorods in surface-enhanced Raman scattering, polarization of light, and photocatalysis has been measured, and the reasons for their high performance are discussed.
\end{abstract}

\section{Introduction}

Collective oscillations of free electrons on the surface of metal nanoparticles (NPs) caused by exposure to light, called surface plasmon resonance (SPR), have been used to color stained glass for the use in churches $[1,2]$. Lowered melting point and changed band structure (quantum size effect) are also interesting phenomena observed for metal NPs, so they are being studied actively $[3,4]$. Such characteristics can be optimized through the precise control of the morphology of metal NPs. Hence, the NPs have diverse application fields such as photocatalysis, (bio)sensing, and surface-enhanced Raman scattering (SERS) [5-7]. Finding simple, inexpensive ways to fabricate morphology-controlled metal NPs has thus been one of the main themes of recent research in this field [8].

"Top-down" and "bottom-up" approaches are both used to fabricate metal NPs, involving, for example, laser abrasion of bulk metal and accumulation of metal atoms, respectively.
"Bottom-up" approaches normally allow more precise control of morphology than "top-down" ones [9]. In the case where metal ions are the building blocks in a "bottom-up" approach, reduction of the ions leads to the formation of metal atoms, which aggregate through Van der Waals forces to form metal NPs. During the formation of metal NPs, their size, shape, and aggregation can be controlled by choosing appropriate rates of nuclear formation and growth, and/or promoting anisotropic growth by stabilizing specific crystal facets on the surface of metal NPs [10]. Templates with nanosized pores (so-called hard templates) can also be used to fabricate morphology-controlled metal NPs [11]. When hard templates are used, treatments to control dispersion state and immobilization of metal NPs on/in matrices are unnecessary, making such templates a simple fabrication procedure suitable for practical applications.

In this paper, the fabrication of metal NPs using modified seed-mediated growth, which does not use hard templates, and the properties of the resulting metal NPs including SERS 

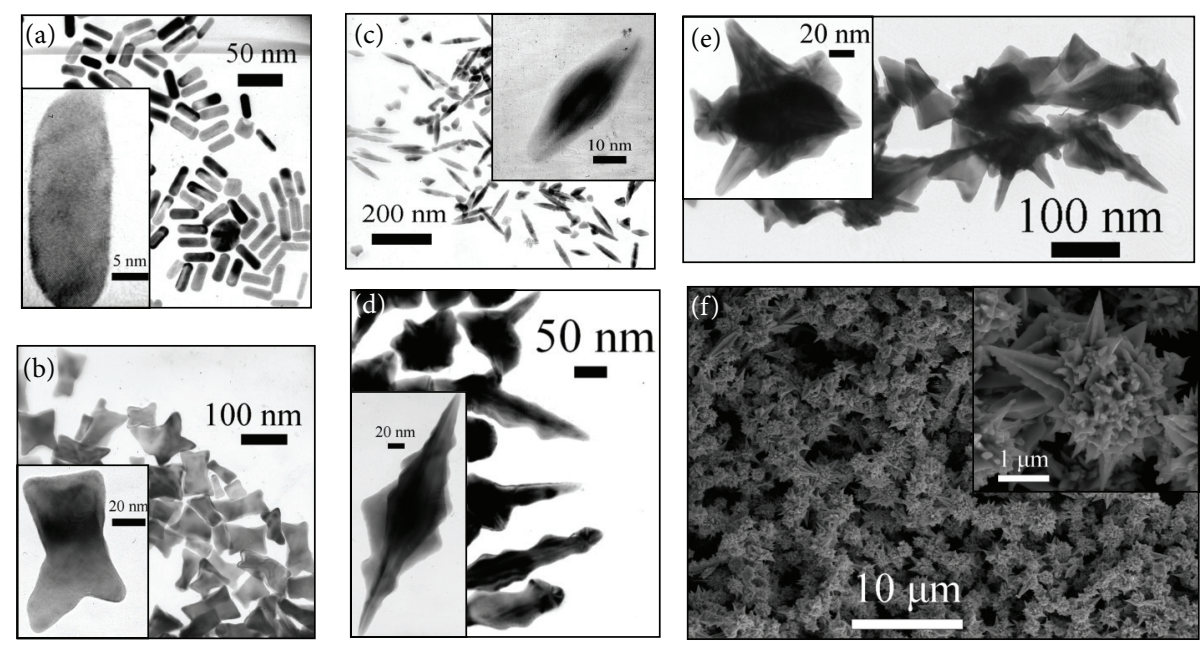

FiguRE 1: Electron microscope images of AuNPs prepared via seed-mediated growth with (a) rod, (b) dog-bone, (c) bipyramidal, (d) roughened bipyramidal, (e) multibranched, and (f) large multibranched morphologies. Magnified images are shown in insets. Reproduced with permission from [18]. Copyright 2009 Elsevier.

$[12,13]$ are first examined. A different method to fabricate metal NPs using mesoporous oxides $[14,15]$ as hard templates and the properties including polarization of light and photocatalysis of the resulting metal NPs are then discussed.

\section{Fabrication of Metal NPs without Hard Templates}

When metal NPs are fabricated via a "bottom-up" approach, metal ions in solution are often used as the source of metal. Metal NPs can be obtained by adding a surface-stabilizing agent, such as a surfactant, and a reductant to the solution. Because gold, platinum, and silver possess low ionization tendencies for metals, they scarcely react to surrounding substances, so controlling the morphology of their NPs is easy compared with those of other metals [16, 17]. In particular, gold nanoparticles (AuNPs) can form various morphologies because of their low ionization tendency, so many researchers have explored simple, inexpensive fabrication methods to prepare morphology-controlled AuNPs [18, 19]. From the perspective of SPR characteristics, rod-shaped NPs (nanorods (NRs)) exhibit two-SPR modes because of their shape anisotropy, while multibranched NPs with many sharp apices show an abnormally strengthened electromagnetic field around themselves [20]. To fabricate metal NPs with such unique SPR-related characteristics, appropriate selection of starting materials is of course required besides the precise control of reaction conditions including temperature, $\mathrm{pH}$, and ionic strength. Some typical examples are described in the following sections.

2.1. AuNPs with Controlled Shape Prepared by Changing the Morphology of Seeds [21]. Seed-mediated growth produces NPs by completely separating nuclear formation and growth stages $[22,23]$. AuNPs with various shapes can be obtained using this method, as shown in Figure 1, simply by changing the morphology of seed particles formed in the nuclear formation stage. For example, we prepared single crystalline $(\sim 1.5 \mathrm{~nm})$ and multiple twin $(\sim 4 \mathrm{~nm})$ particles as seeds and reduced their sizes in a comproportionation reaction using a growth solution containing $\mathrm{Au}^{3+}$ ions. To confirm the occurrence of the comproportionation reaction, optical extinction spectra were measured, as shown in Figure 2. The extinction coefficient at $400 \mathrm{~nm}$ corresponded to an $\mathrm{Au}^{3+}$ ionrelated compound. The degree of the decrease in the extinction coefficient at $400 \mathrm{~nm}$ of a mixture of growth solution and water was smaller than that of a mixture of growth and seed solutions. This indicated that $\mathrm{Au}$ atoms in the seeds reacted with $\mathrm{Au}^{3+}$ ions in the growth solution and both were converted to $\mathrm{Au}^{+}$ions in the comproportionation reaction. The relationship between the morphologies of seeds and AuNPs is illustrated in Figure 3. In the case where single crystalline seeds with a diameter of $\sim 1.5 \mathrm{~nm}$ were used, the shape of the resulting AuNPs gradually changed from NRs (Figure 1(a)) to multibranched NPs (Figure 1(e)) via a dogbone shape (Figure 1(b)) by lengthening the comproportionation reaction time. In contrast, when multiple twin seeds with a size of $\sim 4 \mathrm{~nm}$ were used, the shape of the resulting AuNPs gradually changed from bipyramidal (Figure 1(c)) to multibranched (Figure 1(e)) as the comproportionation reaction time was extended. The size of the multibranched AuNPs increased as the reaction time was increased; the maximum particle size was larger than $1 \mu \mathrm{m}$ (Figure 1(f)). Large multibranched AuNPs were also obtained without addition of a seed solution, suggesting that the seed particles completely dissociated when the comproportionation reaction was allowed to proceed for $10 \mathrm{~min}$. These results revealed that the morphology of AuNPs can be controlled simply by modifying the size and/or morphology of seeds via the comproportionation reaction. 

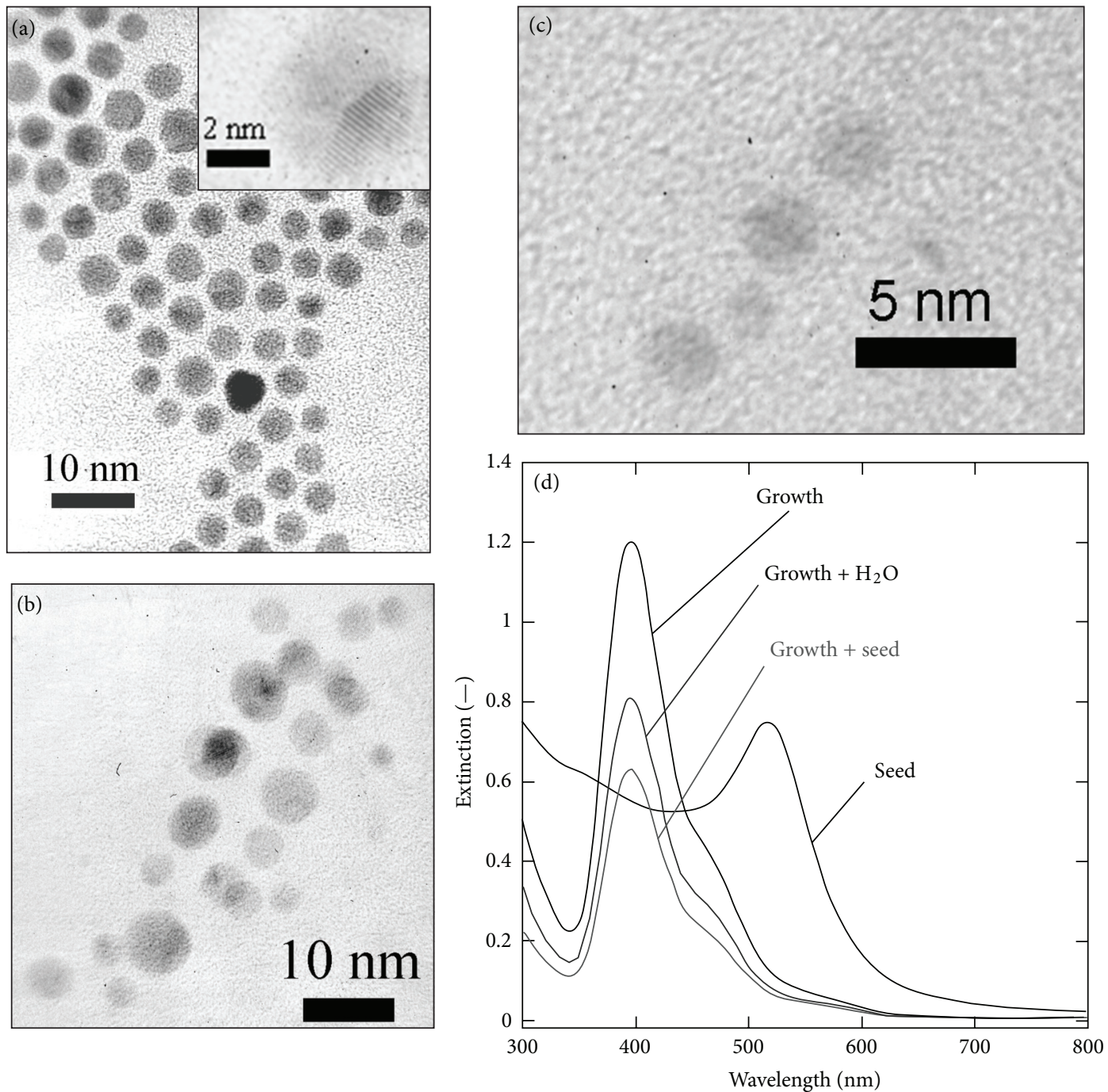

FIGURE 2: Citrate-stabilized seed particles. (a) TEM and HRTEM images of as-prepared particles. TEM images of the particles (b) $10 \mathrm{~s}$ and (c) $20 \mathrm{~s}$ after being added to the growth solution. (d) Optical extinction spectra of the seed and growth solutions, a mixture of the seed (1 mL) and growth $(2 \mathrm{~mL})$ solutions, and a mixture of the growth solution $(2 \mathrm{~mL})$ and $\mathrm{H}_{2} \mathrm{O}(1 \mathrm{~mL})$. Reproduced with permission from [18]. Copyright 2009 Elsevier.

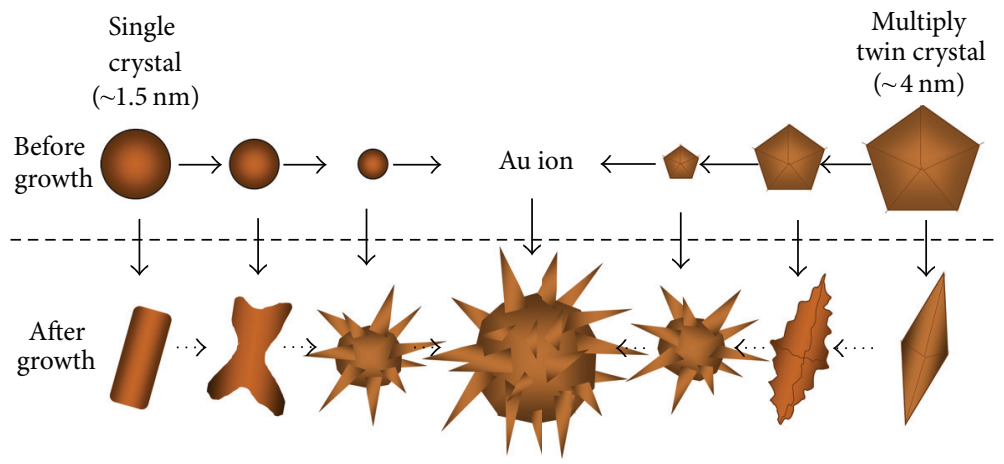

Figure 3: Relationship between the morphologies of seeds and grown AuNPs. Reproduced with permission from [18]. Copyright 2009 Elsevier. 


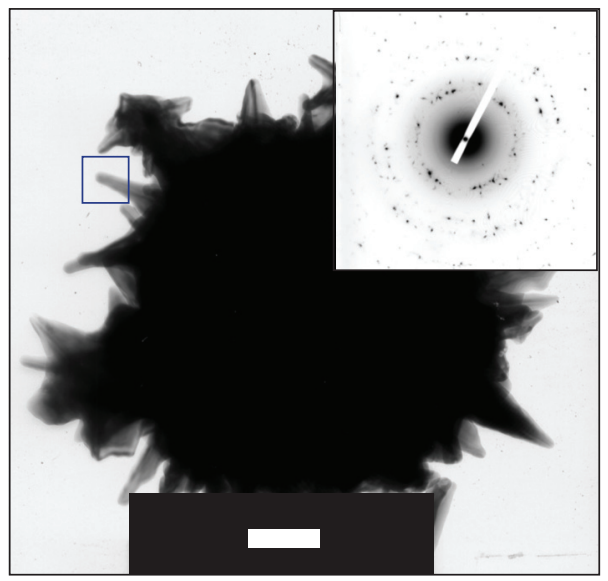

(a)

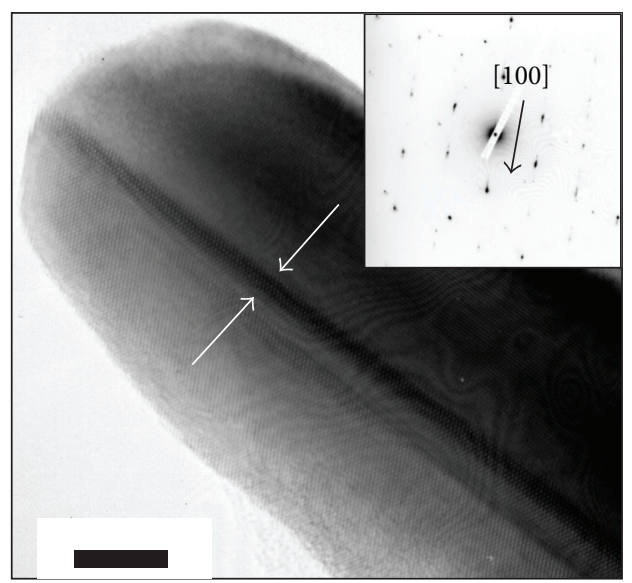

(b)

FIGURE 4: (a) TEM image of an isolated multibranched AuNP. (b) HRTEM image of the branch enclosed by the blue square in (a). The white arrows indicate the position of twin defects. SAED patterns are shown as insets. The white and black scale bars are 100 and $5 \mathrm{~nm}$, respectively. Reproduced with permission from [21]. Copyright 2009 Elsevier.

\subsection{Precise Control of the Shape of Multibranched AuNPs [24].} When AuNPs are prepared by conventional liquid phase synthesis, they normally form particles to minimize their surface energy, resulting in the formation of isotropic $\mathrm{Au}$ nanopolygons/spheres, because gold forms face-centered cubic crystals $[25,26]$. However, the multibranched AuNPs obtained (Figures 1(e) and 1(f)) are partly anisotropic and possess many sharp apices, which strongly enhances the electromagnetic field near the surface of the particles compared with isotropic/spherical AuNPs. Several methods to fabricate AuNPs with multibranched morphology have been reported [27-31]; however, the precise control of their morphology is still very difficult to achieve. We thus investigated the growth mechanism of multibranched AuNPs using a high-resolution transmission electron microscopy (HRTEM) and selectedarea electron diffraction (SAED), as presented in Figure 4. It was concluded that the probable growth mechanism involved a combination of the effects of defect formation in AuNPs and deposition of a small amount of silver atoms on AuNPs. Specifically, in the SAED pattern of an isolated multibranched AuNP (inset of Figure 4(a)), Debye-Scherrer rings are observed, indicating that the particle is polycrystalline. Such particles do not form NRs or cubes but instead assemble into complex structures like multibranched AuNPs. The HRTEM image of a branch enclosed by a blue square in Figure 4(b) shows the existence of stacking faults along the longer axis of the branch (indicated by arrows). The presence of stacking faults is also confirmed by the observation of line reflections along the [lll 100 d direction in the SAED pattern. These results suggest that the branches grew in the $\left[\begin{array}{lll}1 & 0 & 0\end{array}\right]$ direction from defect sites in the polycrystalline core particles. It was also found that underpotential deposition $[32,33]$ of silver on growing AuNPs played an important role in their morphology [24]. Based on the revealed growth mechanism of the particles, the size and morphology of multibranched AuNPs were precisely controlled through the careful selection of the concentrations of seeds, silver ions, and organic additives in the growth solution (Figure 5). Organic additives such as cyclohexane and acetone were added to tighten and loosen, respectively, the micelle structure of cetyltrimethylammonium bromide (CTAB) in the solution [34-37], allowing the length of branches to be modified.

\subsection{Control of AuNR Assemblies and Their SPR and SERS} $[38,39]$. The gold nanorods (AuNRs) shown in Figure 1(a) exhibit two SPR modes because of their anisotropy. The modes ascribed to the oscillations in the directions of the short and long axes resonate with light of shorter and longer wavelength, respectively. The mode that resonates with light of longer wavelength red shifts significantly as the aspect ratio of the AuNRs is increased [40-42]. This characteristic is advantageous to their practical application in wavelengthselective SPR devices. However, AuNRs tend to align parallel to each other as the solvent evaporates, which leads to a capillary force between AuNRs [43-47]. The smectic-like structure (side-to-side assembly) of AuNRs diminishes their SPR characteristics. Conversely, SPR appears more strongly in AuNRs assembled in an end-to-end fashion [48]. Therefore, the control of the assembly and length of AuNRs is important in terms of their SPR properties. In this regard, we prepared AuNRs of controlled length by altering the conditions used for seed-mediated growth (Figure 6). The AuNRs could be induced to assemble in an end-to-end fashion by controlling the concentration of surface stabilizer $(\mathrm{CTAB})$ in solution (Figure 7$)$. In practice, the solution was centrifuged and $\mathrm{H}_{2} \mathrm{O}$ substituted for the supernatant to decrease the concentration of CTAB. To increase the concentration of CTAB, it was just added to the solution. The endto-end assembly of AuNRs presumably occurred because of the stronger affinity of CTAB for the $\left\{\begin{array}{lll}1 & 0 & 0\end{array}\right\}$ and/or $\left\{\begin{array}{lll}1 & 1 & 0\end{array}\right\}$ facets on the sides of the AuNRs, which have larger surface energy than the $\left\{\begin{array}{lll}1 & 1 & 1\end{array}\right\}$ facet on the ends of AuNRs [49]. In other words, the detachment of surfacestabilizing CTAB in the solution with a low concentration of 


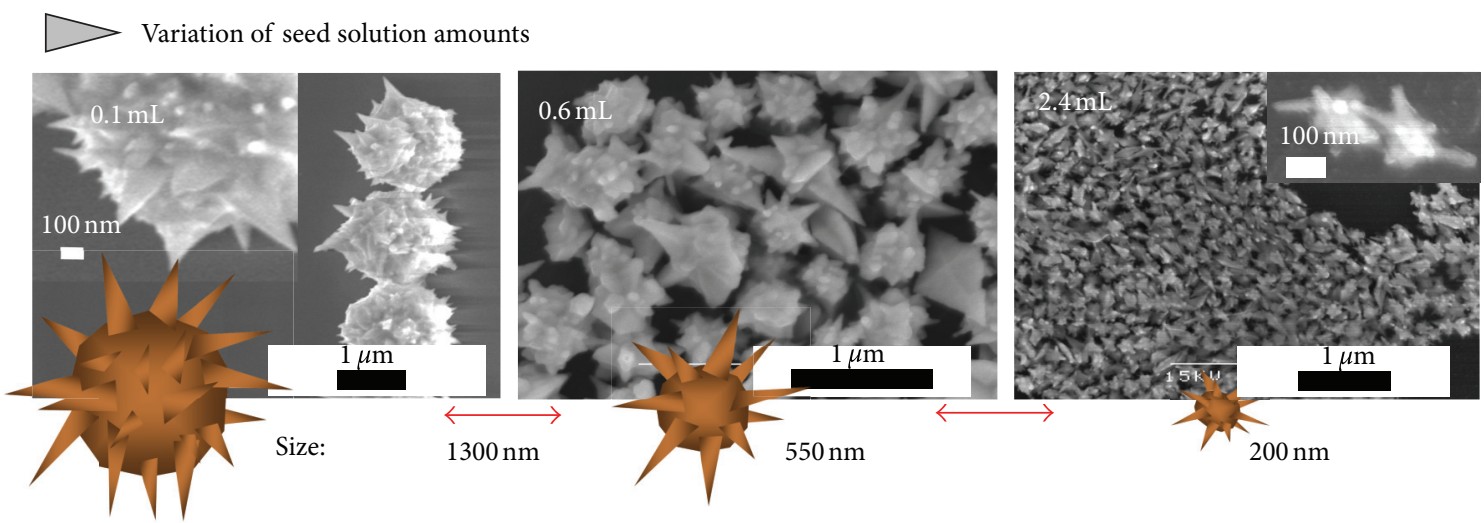

(a)

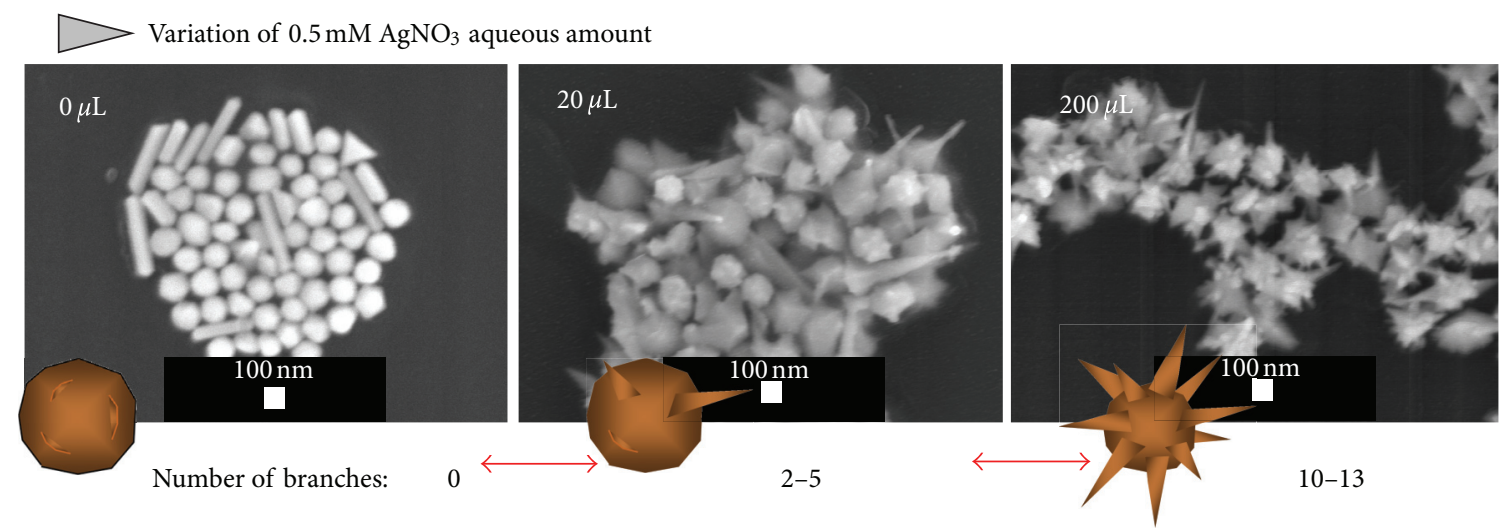

(b)

Variation of additives

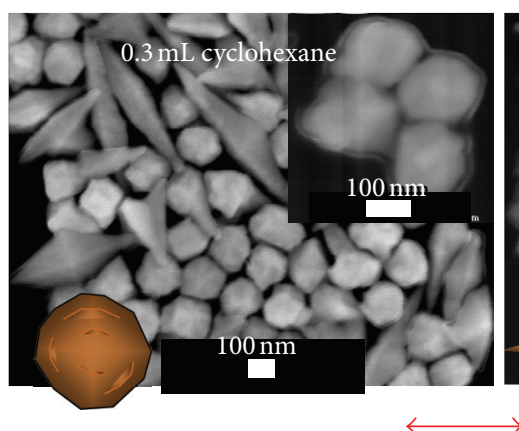

Length of branches: a few $n m$

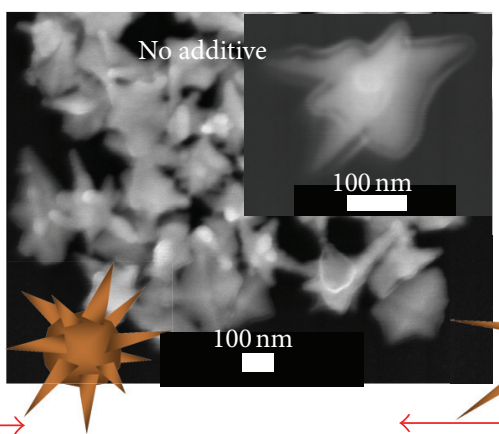

$50-80 \mathrm{~nm}$

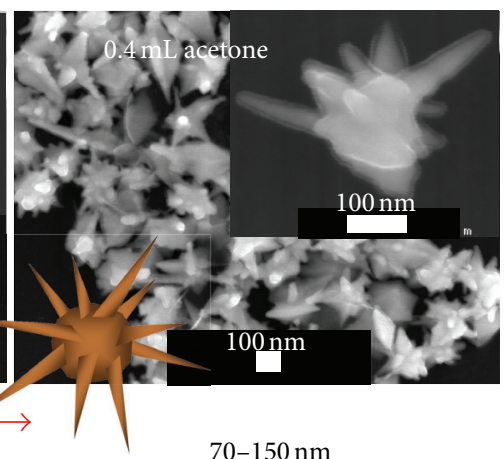

$70-150 \mathrm{~nm}$

(c)

FIGURE 5: SEM images and illustrations of morphology-controlled multibranched AuNPs. Reproduced with permission from [21]. Copyright 2009 Elsevier.
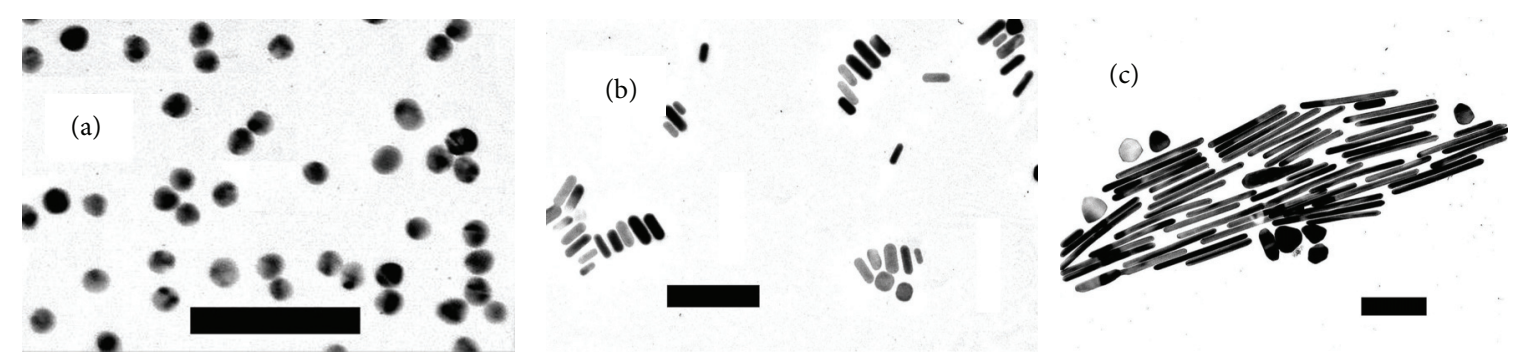

Figure 6: TEM images of AuNRs of different lengths. Reproduced with permission from [32]. Copyright 2008 American Chemical Society. 


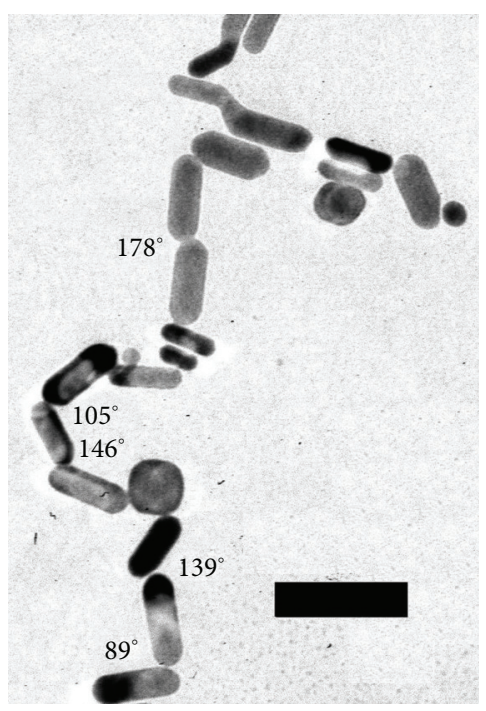

(a)

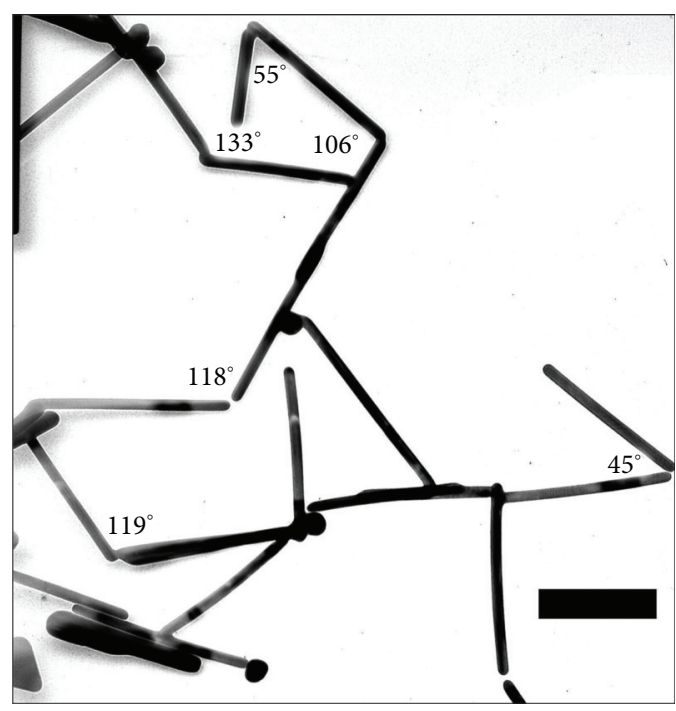

(b)

Figure 7: TEM images of end-to-end-connected AuNRs shown in Figures 6(b) and 6(c). Reproduced with permission from [32]. Copyright 2008 American Chemical Society.

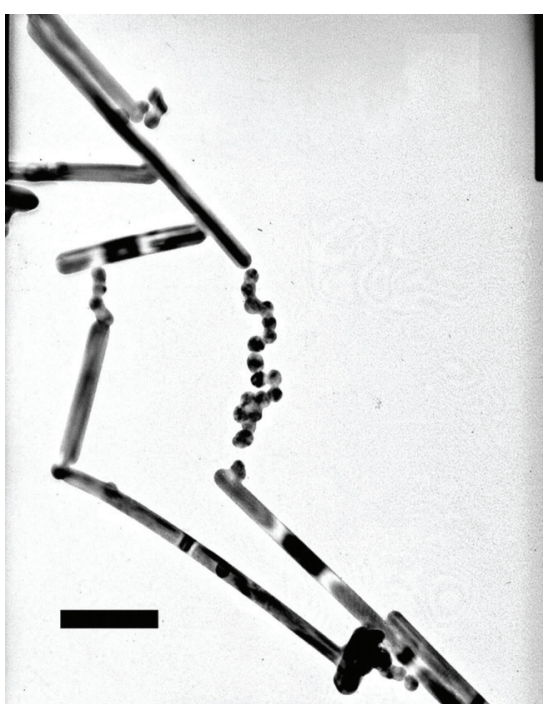

(a)

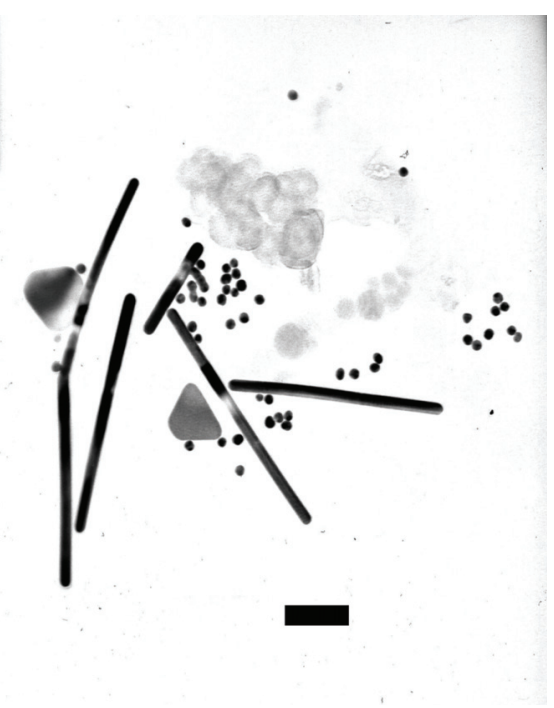

(b)

FIGURE 8: TEM images of CTAB-covered AuNRs after reaction with (a) citrate-stabilized AuNSs and (b) CTAB-stabilized AuNSs. The bare ends of AuNRs adsorb the citrate-stabilized AuNSs, whereas CTAB-stabilized AuNSs only accumulate near the sides of AuNRs. CTAB tends to be adsorbed by the sides of AuNRs in solutions containing a low concentration of CTAB. Scale bars are $100 \mathrm{~nm}$. Reproduced with permission from [32]. Copyright 2008 American Chemical Society.

CTAB started from the ends of AuNRs because of their low affinity, which led to an end-to-end assembly of the AuNRs (Figure 8). Although assembly in an end-to-end fashion continued as time progressed, the degree of connection could be controlled by increasing the concentration of CTAB in the solution (Figure 9). The new peaks appeared at the wavelengths longer than $800 \mathrm{~nm}$ in Figure 9(a) could be attributed to the coupled SPR modes, of end-to-end AuNR assemblies. Moreover, end-to-end AuNR assemblies with/without connecting molecules (CTAB) could be prepared individually
(Figure 10). End-to-end assemblies of AuNRs with CTAB in the gaps between them could be converted back into dispersions of single AuNRs by increasing the concentration of CTAB.

A suspension of end-to-end-connected AuNRs was dropcast onto a glass slide and air-dried to obtain a film sample. The morphology of this film was unlike that of a side-toside-assembled AuNR suspension, as shown in Figure 11. Their extinction spectra were also different; only the film prepared from end-to-end-connected AuNRs exhibited two 


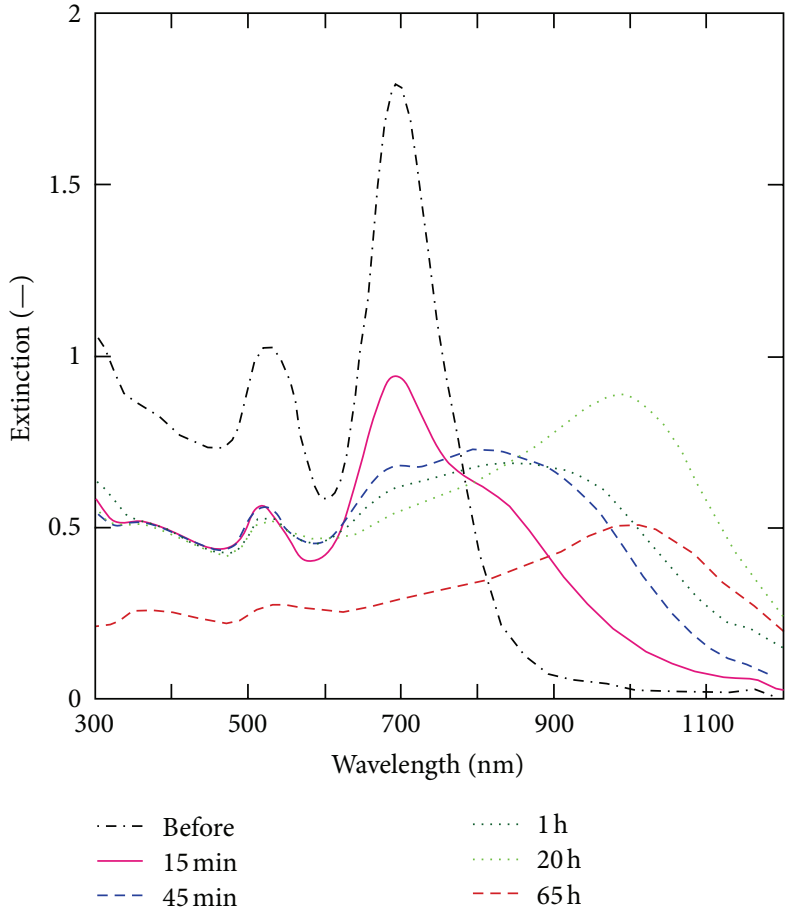

(a)

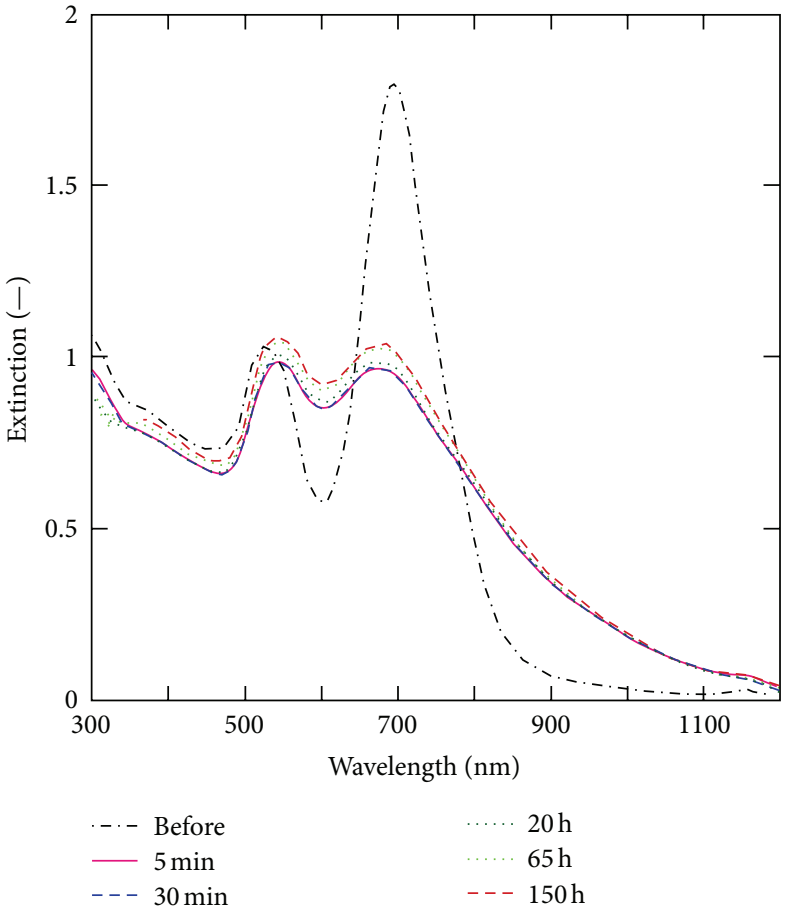

(b)

FIGURE 9: Optical extinction spectra of solutions of AuNRs with an aspect ratio of 3 prepared by adding (a) $40 \mu \mathrm{L}$ of $1 \mathrm{mM}$ sodium citrate and (b) $0.5 \mathrm{~mL}$ of $40 \mathrm{mM} \mathrm{CTAB} 5 \mathrm{~min}$ after the addition of $60 \mu \mathrm{L}$ of $1 \mathrm{mM}$ sodium citrate. The times in (a) and (b) are the time intervals after the addition of sodium citrate and CTAB, respectively. The unchanged spectra in (b) with time indicate the end of growth of end-to-endconnected AuNRs. Reproduced with permission from [32]. Copyright 2008 American Chemical Society.

distinct extinctions (Figure 12). Because AuNRs assembled in a side-to-side (parallel alignment) fashion show reduced SPR, the two observed extinctions from the end-to-endassembled (linear-aligned) AuNR film were considered to be the intrinsic SPR of AuNRs. In fact, results simulated using Gans' theory indicated that the extinction at $2200 \mathrm{~nm}$ could be assigned to the weakly coupled longitudinal mode of AuNRs with an aspect ratio of $16[50,51]$, whereas that at $800 \mathrm{~nm}$ was attributed to gold nanodiscs, which are a byproduct of AuNRs and can be seen in Figures 6(c), 7(b), and 8(b). The film prepared from end-to-end-assembled AuNRs exhibited strong extinction peaks and high SERS activity (Figure 13). In contrast, the film prepared from side-toside-assembled AuNRs showed low SERS activity. These results indicate that there are two reasons for the high SERS activity of the film prepared from end-to-end-assembled AuNRs: the large enhancement of electromagnetic field because of the strong SPR effect, and the proximity of rhodamine 6G (R6G) to the surface of AuNRs because of the low quantity of CTAB on the surface (and especially the ends) of AuNRs. In other words, end-to-end AuNR assemblies escaped the reduction of their SPR [48], and the strong nearfield light was utilized to excite R6G which could reach very close to AuNR surface due to the absence of CTAB.

\section{Fabrication of Metal NPs with Hard Templates}

As well as soft templates like the surfactants discussed above, hard templates such as mesoporous oxides, anodized oxide layers, and zeolites can also be used to fabricate metal NPs [52-55]. When hard templates are used, the porous structures in the template directly determine the morphology of the resulting metal NPs [56]. Furthermore, if the hard templates are used as a matrix for the final product, the processes required to assemble and immobilize metal NPs prepared by soft templates can be bypassed. For example, when a template with a two-dimensional (2D) structure is used, the shape and/or assembly of metal NPs should be anisotropic and thus exhibit unique anisotropic characteristics. In the next section, the syntheses of metal NPs and NRs using mesoporous oxide templates with tubular pores are reviewed. Because the caliber of tubular mesopores is constant in each template (the porous structure is ascribed to $2 \mathrm{D}$ hexagonal), the diameter of metal NPs/NRs is fixed. Therefore, the SPR of the NPs/NRs is readily controlled because the wavelength of SPR depends only on their aspect ratio.

3.1. Anisotropic Assembly of AuNRs and Polarization Effects [57]. Mesoporous silica with 2D hexagonal structure like MCM-41 and SBA-15 contains curving tubular mesopores, so structural anisotropy is not apparent over a wide range (>several tens of $\mu \mathrm{m}^{2}$ ). A coating of mesoporous silica on muscovite mica is one of the methods used to realize anisotropy by aligning the tubular mesopores over a widerange $[58,59]$. Figure 14 shows electron microscope images, a schematic illustration, and X-ray diffraction (XRD) patterns of a mesoporous silica film grown on mica. Uniaxially aligned, evenly spaced pores were observed in a region of 


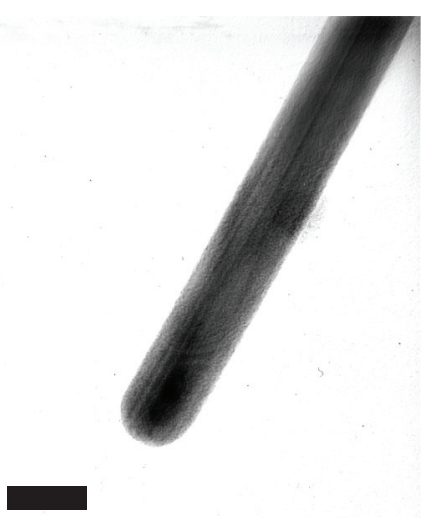

(a)

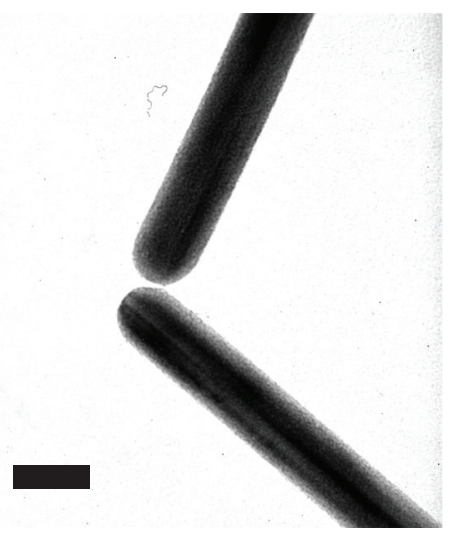

(b)

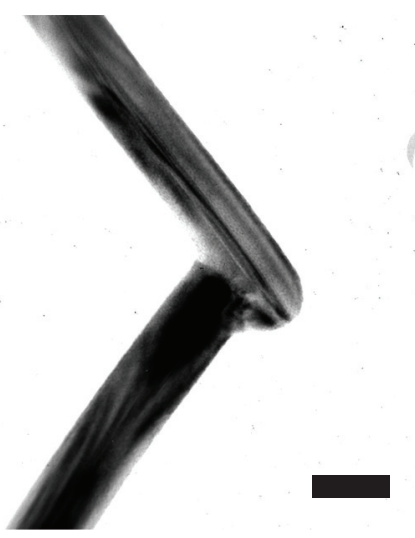

(c)

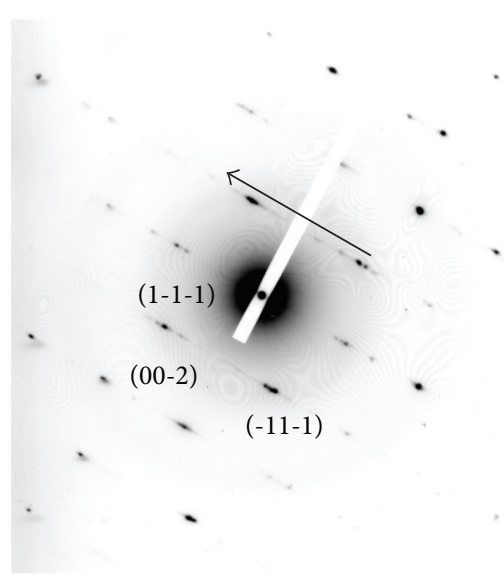

(d)

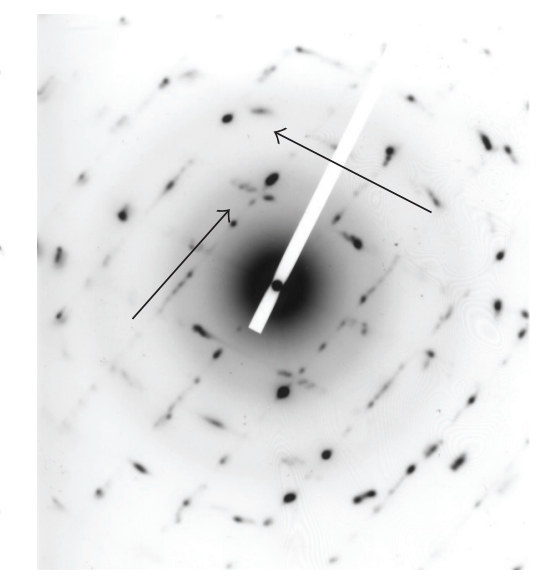

(e)

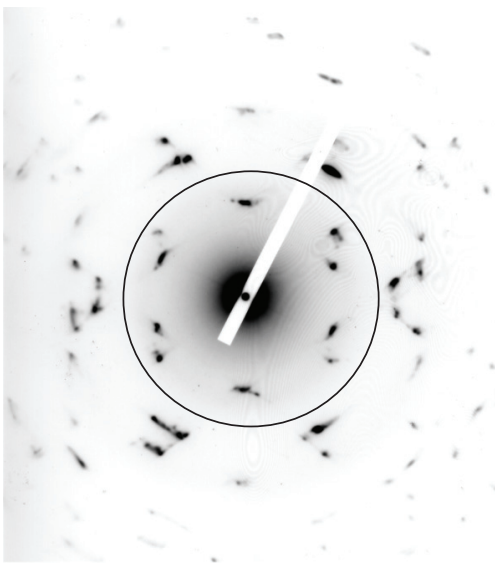

(f)

FIGURE 10: TEM images of (a) isolated and end-to-end-connected AuNRs (b) with and (c) without connecting molecules (CTAB) between them. $(\mathrm{d}-\mathrm{f})$ Corresponding SAED patterns for AuNRs shown in $(\mathrm{a}-\mathrm{c})$, respectively. Scale bars are $20 \mathrm{~nm}$. Reproduced with permission from [32]. Copyright 2008 American Chemical Society.

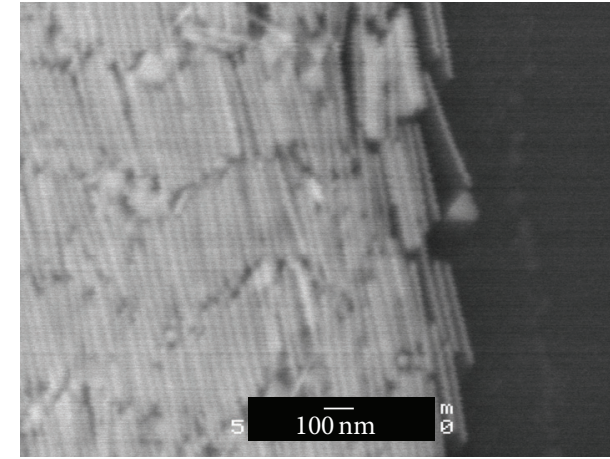

(a) Parallel-aligned AuNRs

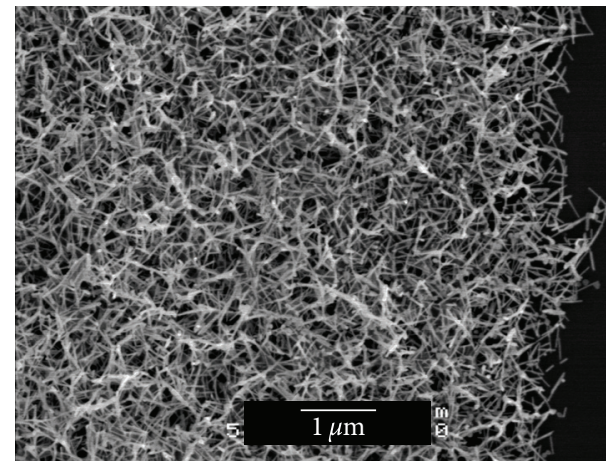

(b) Linear-aligned AuNRs

FIGURE 11: SEM images of self-assembled AuNRs on glass substrates prepared using the concentrated solutions shown in Figures 6(c) and 7(b). Reproduced with permission from [31]. Copyright 2007 American Institute of Physics.

$\sim 1 \mathrm{~cm}^{2}$ at the surface of the film (Figure 14(a)). Similar pores were also observed throughout the depth of the film (Figure 14(b)). These observations confirmed that the prepared film possessed uniaxially aligned tubular mesopores in a wide region, like those illustrated in Figure 14(c). The direction of the longitudinal axis of the tubular mesopores was parallel to the cleavage direction of the mica substrate. The XRD pattern indicated that the planar distance ( $d$-value) of the $\left\{\begin{array}{lll}1 & 0 & 0\end{array}\right\}$ planes of the 2D hexagonal structure of the film was $3.6 \mathrm{~nm}$ (Figure 14(d)). After the deposition of gold into the pores of the film, interesting results were obtained, as presented in Figure 15. The film showed different appearances when it 


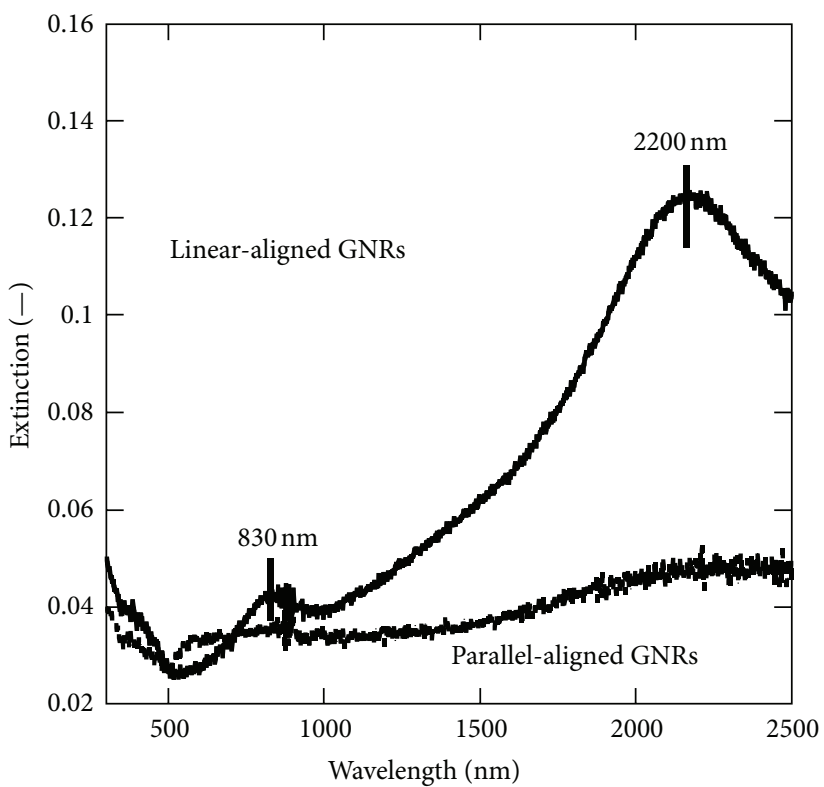

FIGURE 12: Optical absorption spectra of samples shown in Figures 11(a) and 11(b) named parallel-linearaligned (side-to-side-connected) and linear-aligned (end-to-end-connected) AuNRs, respectively. The concentrations of AuNRs in both samples are almost same (about $10^{9} \mathrm{~cm}^{-2}$ ). The spectra include both absorption and scattering by AuNRs. Reproduced with permission from [31]. Copyright 2007 American Institute of Physics.

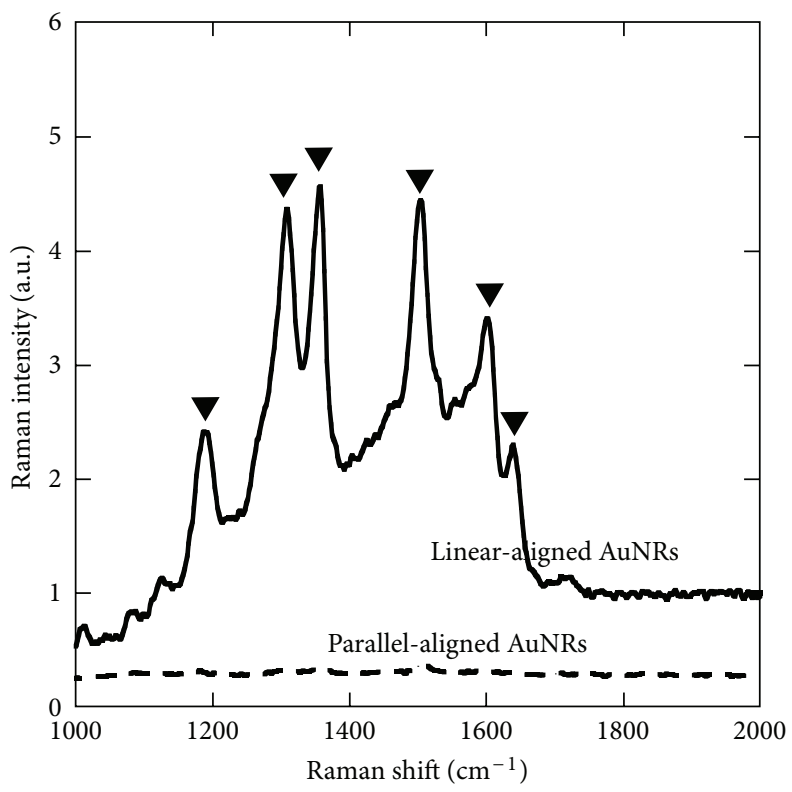

R6G

FIGURE 13: SERS spectra of R6G adsorbed on samples shown in Figures 11(a) and 11(b). Both samples contained accurate concentrations of AuNRs of $10^{6} \mathrm{~cm}^{-2}$ and R6G of $10^{-13} \mathrm{~mol}$ in the detection areas: laser wavelength of $1064 \mathrm{~nm}$; laser power of $0.5 \mathrm{~W}$; excitation spot size of $100 \mu \mathrm{m}$; integration number of 254; and spectral resolution of $2 \mathrm{~cm}^{-1}$. The samples were positioned perpendicular to the excitation source. Reproduced with permission from [31]. Copyright 2007 American Institute of Physics. 


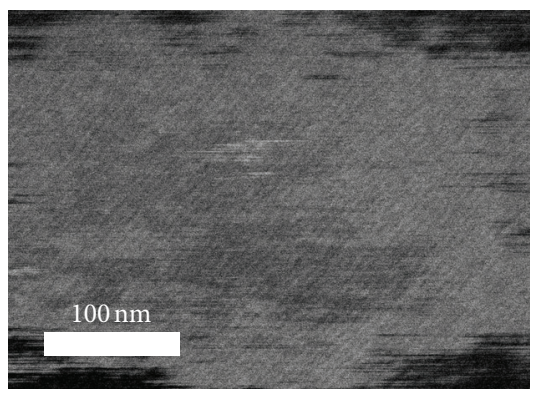

(a)

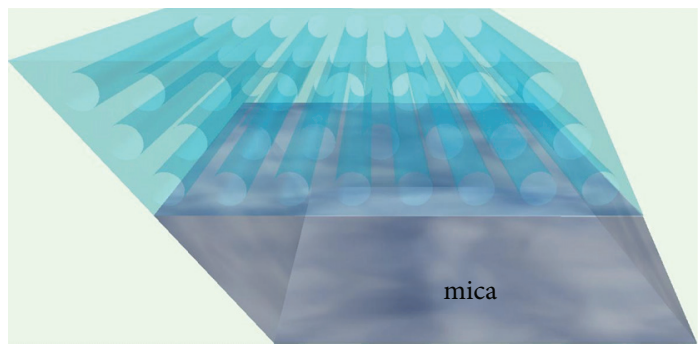

(c)

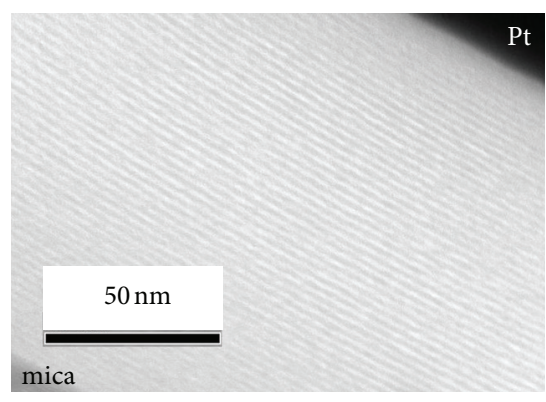

(b)

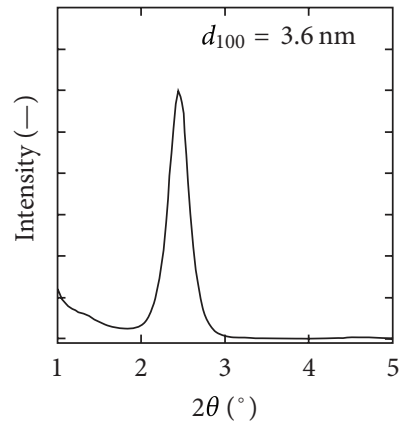

(d)

FIGURE 14: (a) SEM and (b) cross-sectional TEM images, (c) schematic illustration, and (d) XRD pattern of the prepared mesoporous silica on mica. Reproduced with permission from [50]. Copyright 2012 Elsevier.

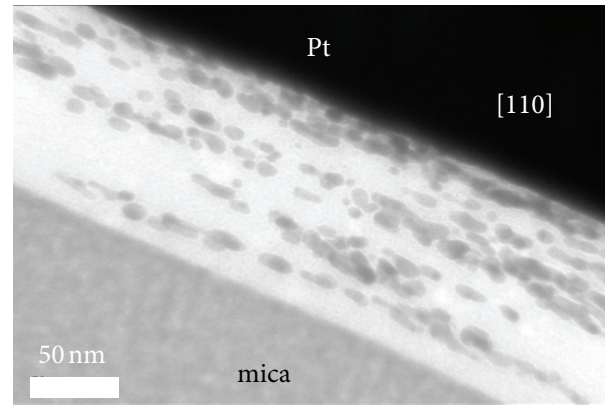

(a)

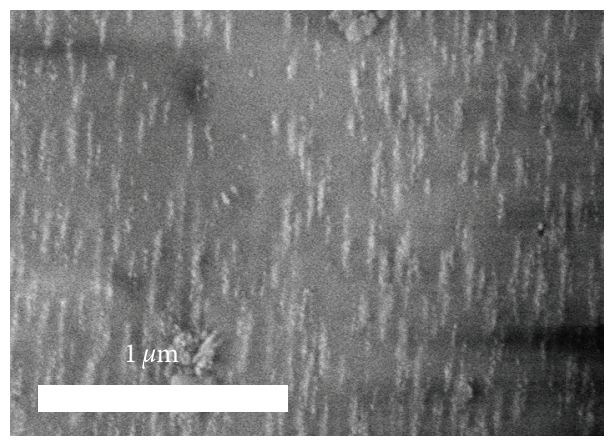

(c)

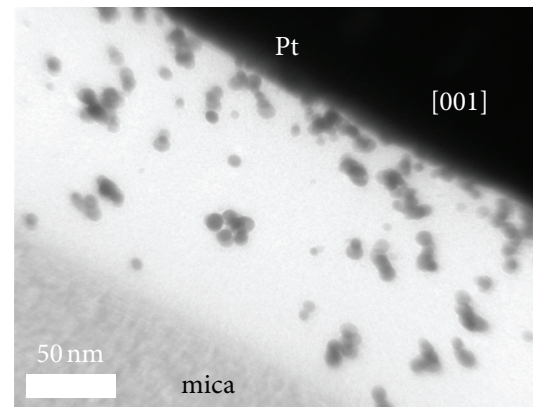

(b)

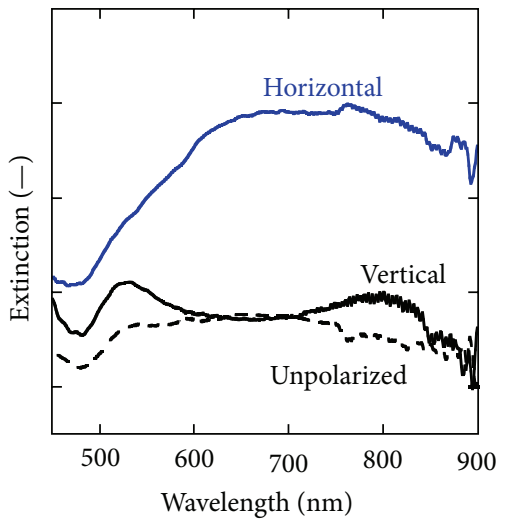

(d)

Figure 15: (a, b) Cross-sectional TEM and (c) surface SEM images and (d) polarized transmission spectra of the prepared chain-like ellipsoidal AuNP-doped mesoporous silica on mica. Reproduced with permission from [50]. Copyright 2012 Elsevier. 


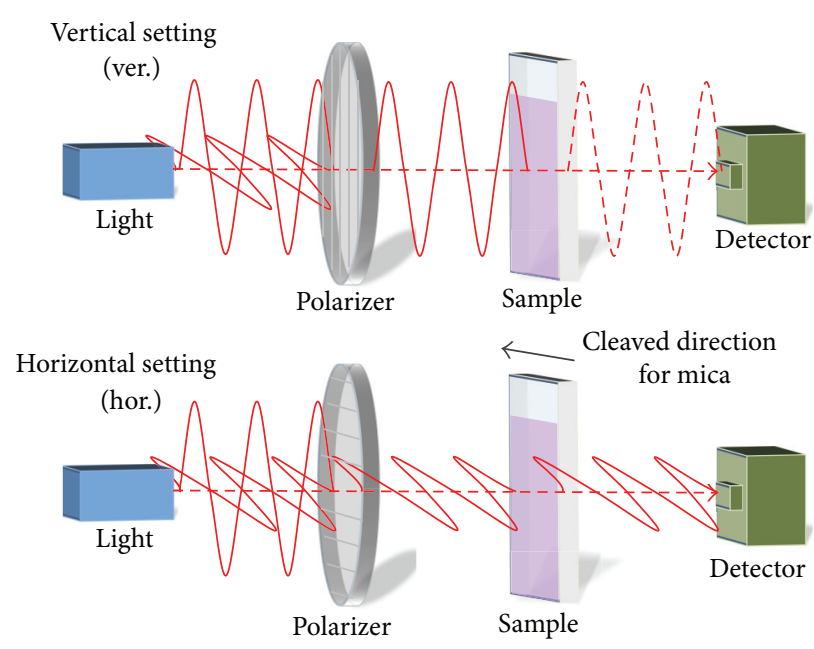

FIGURE 16: Setup for the measurement of polarized transmission spectra. Reproduced with permission from [50]. Copyright 2012 Elsevier.

was observed from two different directions by cross-sectional TEM (Figures 15(a) and 15(b)). The zone axes shown in the images indicate the direction of the $2 \mathrm{D}$ hexagonal structure of the film, which were parallel to the electron beam axis of the TEM. The longitudinal axes of the tubular mesopores were horizontal (from upper left to lower right) and vertical to the images in Figures 15(a) and 15(b), respectively. HRTEM and SAED confirmed that the black particles observed in the film were gold. In Figure 15(a), each AuNP was elliptical with a conjugate diameter of $\sim 3 \mathrm{~nm}$, and the particles were connected to each other in an end-to-end fashion. The connected particles were aligned in one direction to form a straight chain-like structure. In contrast, the AuNPs in Figure 15(b) were spherical with a diameter of $\sim 3 \mathrm{~nm}$ and were not aligned in any direction. These results show that the deposition of gold occurred in the tubular mesopores with a caliber of $\sim 3.5 \mathrm{~nm}$. The chain-like ellipsoidal AuNP assemblies were also clearly observed over a wide region $\left(\sim 1 \mathrm{~cm}^{2}\right)$ with surface scanning electron microscopy (SEM) (Figure 15(c)).

When polarized light, the electric field of which was parallel to the longitudinal axis of the tubular mesopores (the polarizer was set horizontally (hor.), as shown in Figure 16), was used to measure the optical transmission of the film, a broad extinction at $\sim 700 \mathrm{~nm}$ was observed (hor. in Figure 15(d)). In contrast, light with orthogonal polarization to hor. (the polarizer was set vertically (ver.), as shown in Figure 16) showed an extinction at $520 \mathrm{~nm}$ (ver. in Figure 15(d)). These results indicate that the film exhibited macroscopic anisotropic SPR. This is because the transverse SPR mode of the chain-like AuNP assemblies shows a sharp extinction peak at around $520 \mathrm{~nm}$, while the longitudinal SPR mode is induced by light of longer wavelength [1]. Namely, the light of hor. and ver. polarization excited the longitudinal and transverse SPR modes of the chain-like AuNP assemblies, respectively. The spectrum obtained using ver. polarization also contained a small peak of unknown origin at $800 \mathrm{~nm}$. The results reveal that, although similar materials have been reported elsewhere $[52-55,60,61]$, such films are an alternative to conventional organic polarizers because of the advantages including the large extinction coefficient of AuNPs and tunable SPR wavelength.

3.2. Precise Control of the Length of Silver NRs [62]. The diameter of metal NRs deposited in mesoporous silica with 2D hexagonal structure is readily controlled. However, it is difficult to control the length of metal NRs deposited in tubular mesopores. Controlling the length of metal NRs in mesoporous templates has been attempted by changing the ionic strength and/or temperature of the growth solution of metal NRs. However, the precise control of length was not achieved $[63,64]$. With the aim of producing metal NRs of controlled length, we focused on the light-induced oxidation of silver based on the interaction between silver and titania $\left(\mathrm{TiO}_{2}\right)$ crystals. Silver is oxidized when the SPR of silver nanoparticles (AgNPs) in contact with $\mathrm{TiO}_{2}$ is excited and the excited electrons of silver transfer to $\mathrm{TiO}_{2}$, resulting in a lack of electrons in the AgNPs [65]. We oxidized silver nanorods (AgNRs) by irradiating tubular mesopores of silica templates containing $\mathrm{TiO}_{2}$ nanocrystals with light. After/during the deposition of AgNRs via chemical reduction, the samples were exposed to light with a wavelength that induced the SPR of AgNRs, which allowed the precise control of the length of AgNRs in the tubular mesopores. Figure 17 shows an XRD pattern and TEM images of the $\mathrm{TiO}_{2}$-doped mesoporous silica template. Anatase $\mathrm{TiO}_{2}$ nanocrystals were deposited and dispersed in the mesoporous silica framework. The extinction spectra of samples prepared with/without irradiation with light of 570-690 nm after deposition of AgNRs are presented in Figure 18. Irradiation of the sample with light of 570-690 nm after silver deposition resulted in decreased absorbance in the same wavelength region as that of the incident light and increased absorbance at longer wavelength. This was presumably caused by the formation of AgNRs that were too long to exhibit SPR. Namely, some of the $\mathrm{Ag}^{+}$ ions generated by the dissociation of SPR-active AgNRs were deposited on the long AgNRs that were unaffected by light irradiation (see the illustration in the inset of Figure 18). 


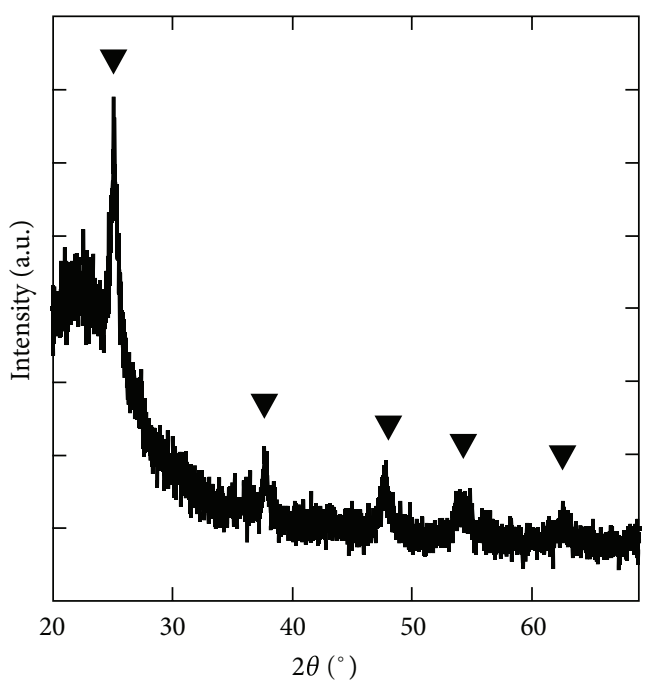

Anatase

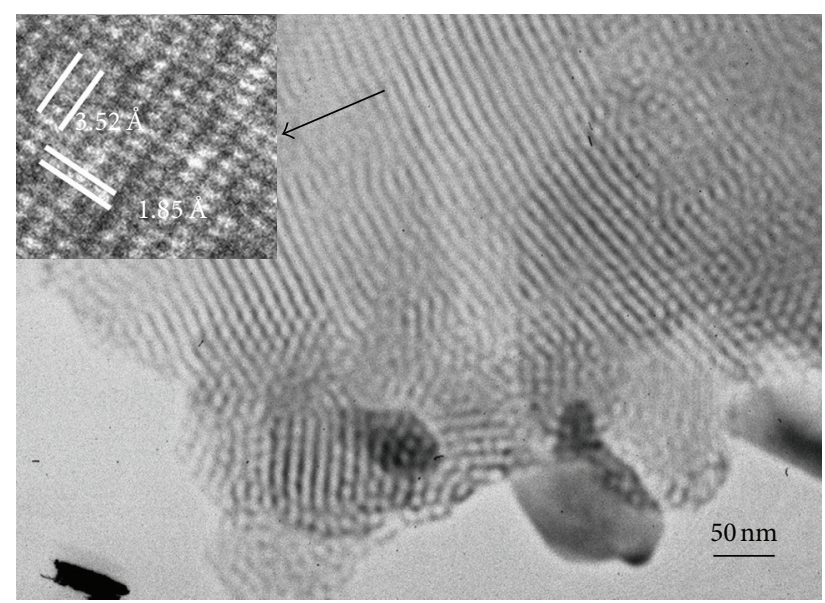

(b)

FIGURE 17: XRD pattern and TEM images of the $80 \mathrm{SiO}_{2} \cdot 20 \mathrm{TiO}_{2}$ template. Reproduced with permission from [53]. Copyright 2011 The Royal Society of Chemistry.

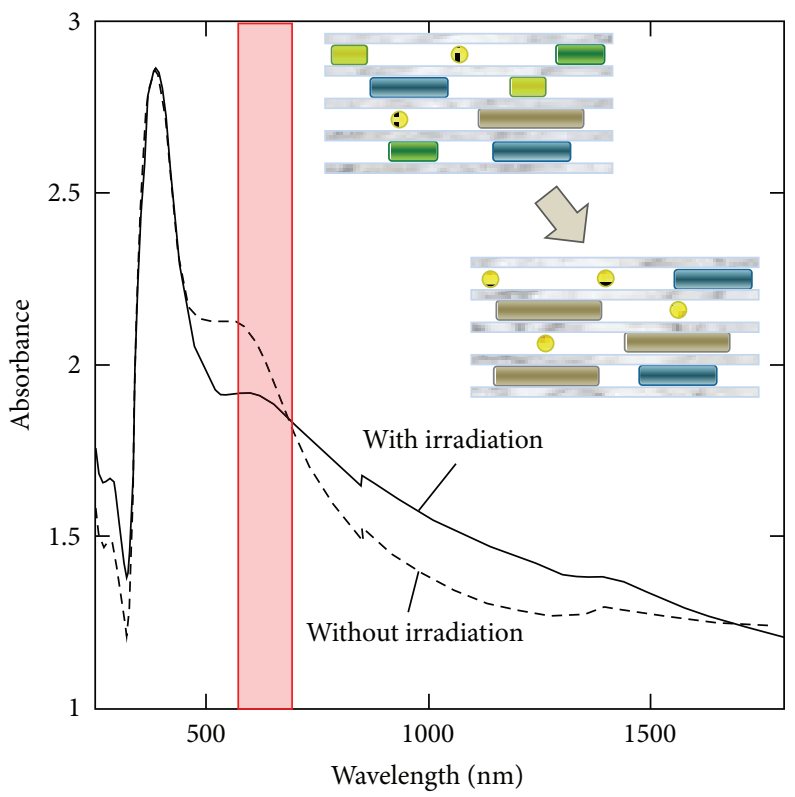

FIGURE 18: DR spectra of samples prepared with/without irradiation with light of 570-690 nm after deposition of AgNRs. The inset shows a schematic illustration of the samples. Reproduced with permission from [53]. Copyright 2011 The Royal Society of Chemistry.

Therefore, the amount of silver atoms in the long AgNRs increased, so the absorbance at longer wavelength was enhanced compared with that of the incident light.

Figure 19 depicts TEM images, histograms showing the aspect ratios of AgNRs, and diffuse reflectance (DR) spectra of samples prepared with/without irradiation of light of specific wavelength during silver deposition. Without irradiation of light, silver was deposited along the inner wall of the tubular mesopores to form AgNRs with various aspect ratios (Figures 19(a) and 19(d)). In contrast, irradiation with light of $490-550 \mathrm{~nm}$ caused the predominant formation of spherical AgNPs (Figures 19(b) and 19(e)). Light of $650-810 \mathrm{~nm}$ produced AgNRs with an aspect ratio of 1-4 (Figures 19(c) and 19(f)). The DR spectrum of the sample prepared without light irradiation contained a peak at $395 \mathrm{~nm}$ that was attributed to both the SPR of spherical AgNPs and transverse SPR mode of AgNRs, and a peak at $600 \mathrm{~nm}$ that was consistent with the longitudinal SPR 


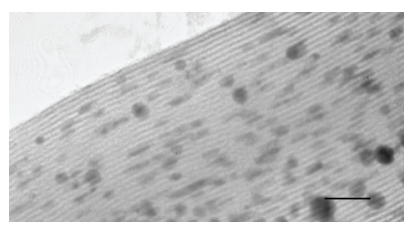

(a)

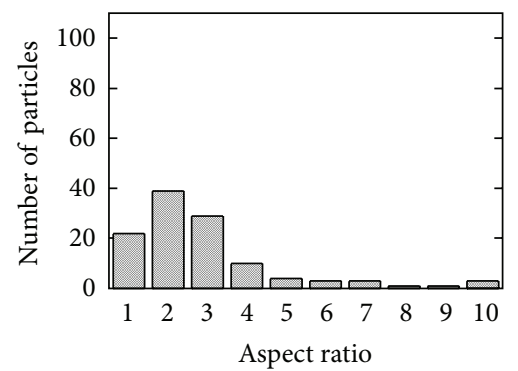

(d)

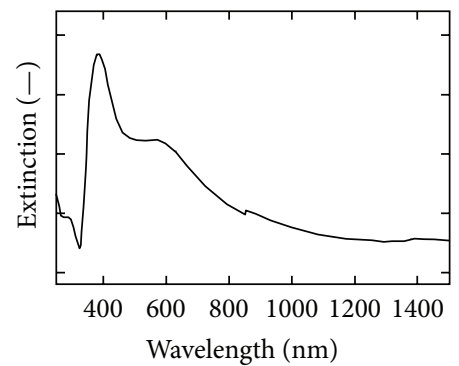

(g)

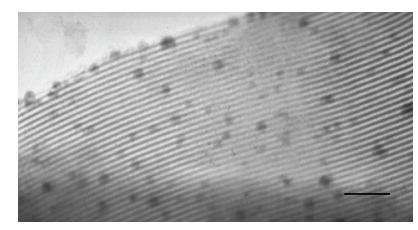

(b)

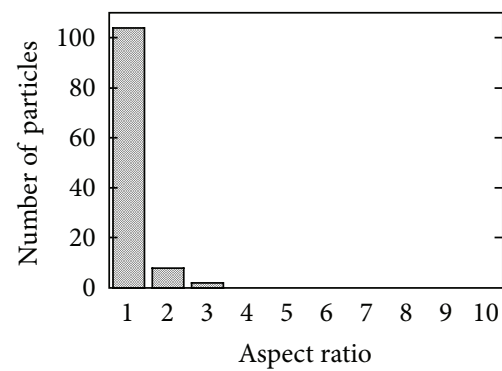

(e)

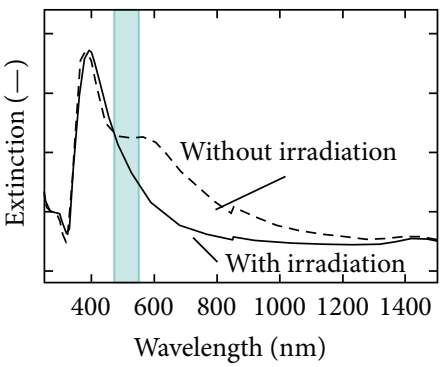

(h)

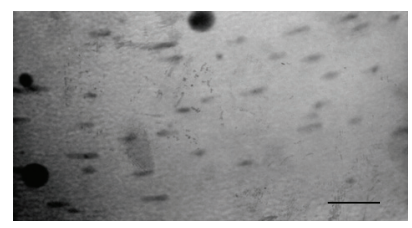

(c)

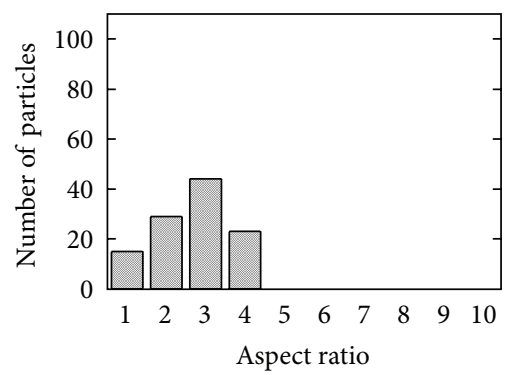

(f)

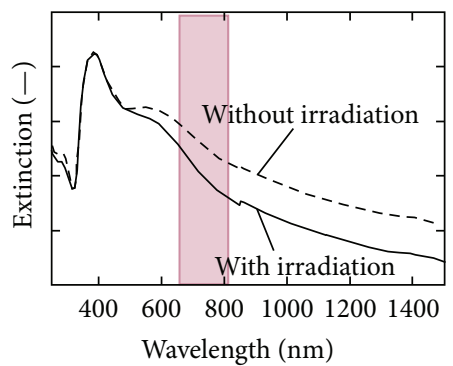

(i)

FIGURE 19: TEM images of samples prepared (a) without and with irradiation of light of (b) 490-550 and (c) 650-810 nm (scale bars: 100 nm). (d, e, and f) Histograms showing the distribution of aspect ratios of the AgNRs observed in the samples shown in (a, b, and c), respectively. (g, $\mathrm{h}$, and i) The corresponding DR spectra of the samples shown in ( $\mathrm{a}, \mathrm{b}$, and $\mathrm{c}$ ), respectively (the wavelengths of the incident light are indicated by squares). Reproduced with permission from [53]. Copyright 2011 The Royal Society of Chemistry.

mode of AgNRs (Figure 19(g)). The spectrum of the sample prepared under irradiation with light of 490-550 $\mathrm{nm}$ showed only one peak at $398 \mathrm{~nm}$ (Figure 19(h)). Irradiation with light of $650-810 \mathrm{~nm}$ caused a blue shift of the peak at $600 \mathrm{~nm}$ to $580 \mathrm{~nm}$ (Figure 19(i)), which indirectly suggested that the length of the AgNRs was shortened by irradiation with light of this wavelength range. In other words, the exposure to light of a certain wavelength caused a decrease in absorbance at longer wavelength than that of the incident light. This suggested that when the growing AgNRs reached a critical length, the incident light caused SPR excitation, which induced dissociation of AgNRs. As a result, the formation of AgNRs longer than this critical length was prevented. A schematic illustration of the results presented in Figure 19 is provided in Figure 20. These results implied that irradiation with light of a specific wavelength was a promising tool to control the length of AgNRs in tubular mesoporous templates containing anatase nanocrystals.

3.3. Fabrication of AuNP-Doped Mesoporous Oxides with Unique Photocatalytic Activity [66]. Several studies on the deposition of morphology-controlled metal NPs in mesoporous oxide templates have been reviewed above $[53,54,59-$ 61]. One of the most probable applications of such materials is as highly efficient photocatalysts, taking advantage of their strong optical absorption induced by SPR and the large specific surface area of the mesoporous templates. Figure 21 shows TEM images and DR spectra of Au-deposited mesoporous silica templates containing anatase nanocrystals prepared with/without ultraviolet (UV) irradiation. AuNRs and gold nanospheres (AuNSs) were observed in the samples prepared without and with UV irradiation, respectively. The extinction peaks except that at $520 \mathrm{~nm}$ almost disappeared when the sample was exposed to UV light. The peak at $520 \mathrm{~nm}$ was attributed to the SPR of AuNSs and the transverse SPR of AuNRs. The other peaks in the spectrum of the sample prepared without UV irradiation were consistent with the longitudinal SPR of AuNRs. The change of the shape of the AuNPs upon exposure to UV radiation was a result of the photocatalytic activity of the anatase $\mathrm{TiO}_{2}$ contained in the template [66].

The samples also exhibited a strong absorption at $<400 \mathrm{~nm}$ that was related to the band gap of the anatase 


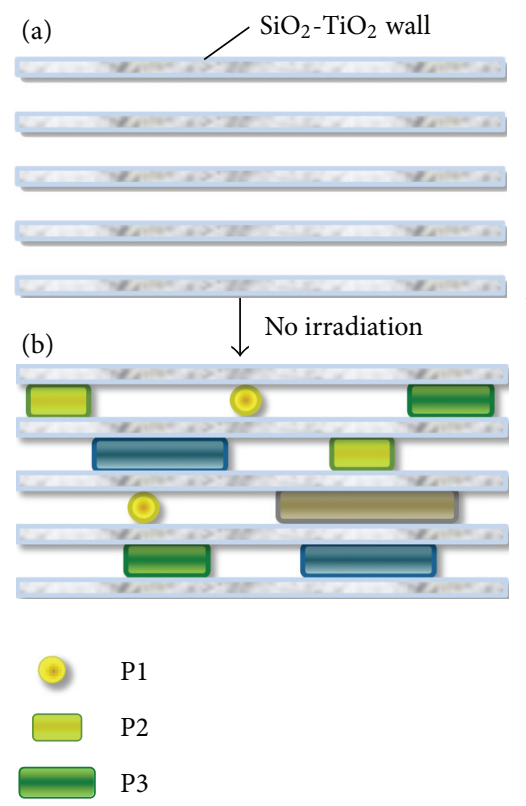

(c)

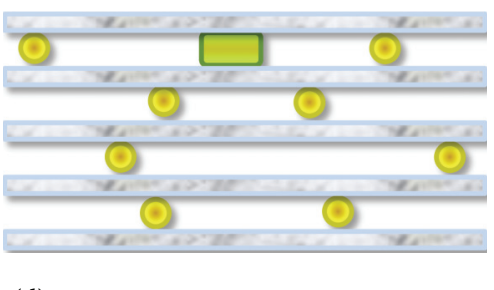

(d)
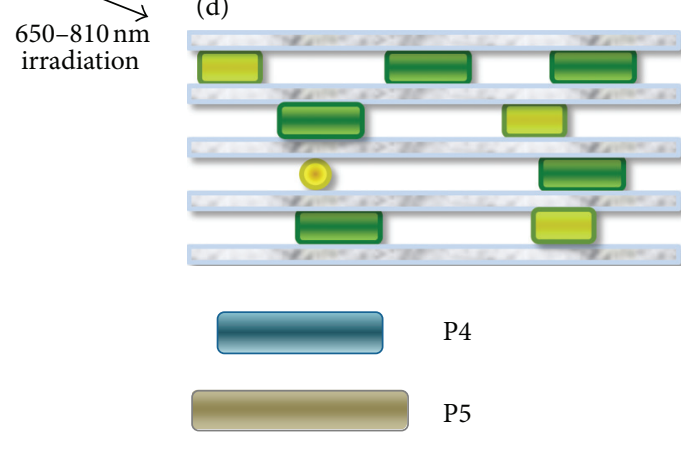

FIgURE 20: Illustration of the results of deposition of AgNRs in tubular mesoporous $\mathrm{SiO}_{2}-\mathrm{TiO}_{2}$ templates with/without light irradiation. Reproduced with permission from [53]. Copyright 2011 The Royal Society of Chemistry.
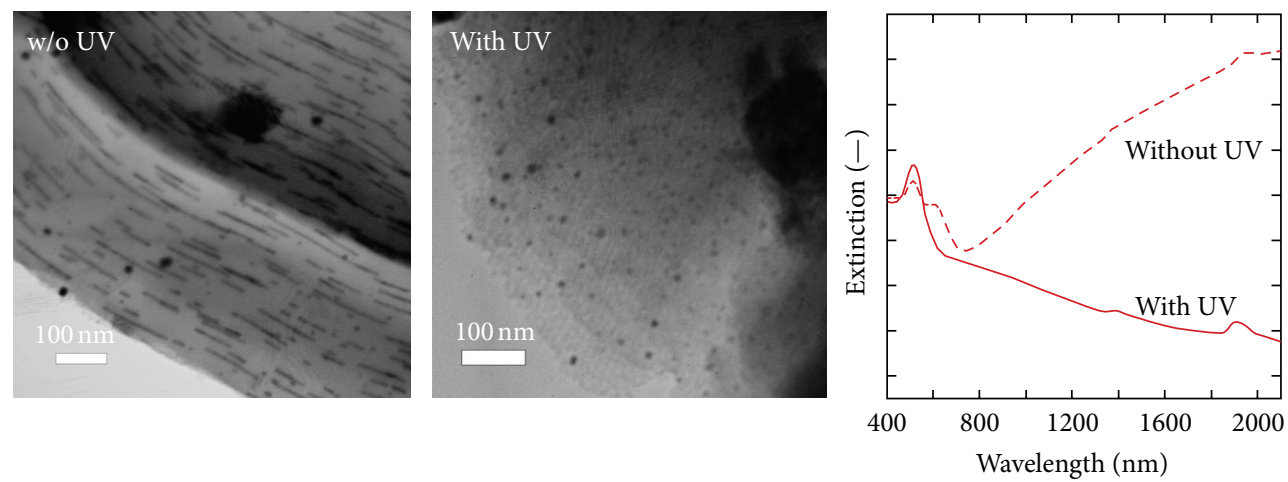

FIgURE 21: TEM images and DR spectra of Au-deposited $80 \mathrm{SiO}_{2} \cdot 20 \mathrm{TiO}_{2}$ samples prepared with/without UV irradiation. Reproduced from [57]. Copyright 2012 Kawamura et al., licensee Springer.

nanocrystals in the templates. Figure 22 shows the photobleaching dynamics of methylene blue (MB) solution by various samples upon UV irradiation. The mesoporous template was required to bleach $\mathrm{MB}$ upon UV irradiation. The deposited AuNPs increased the bleaching rate of MB. This suggested that the photocatalytic activity of the template was improved by the formation of a Schottky barrier between anatase nanocrystals and gold, extending the lifetimes of charge carriers generated by UV irradiation [67]. The deposition of AuNRs increased the bleaching rate of MB more than AuNSs. The quantities of deposited gold in both samples were the same. Thus, it was found that the shape and/or size of AuNPs affected the photocatalytic activity of anatase $\mathrm{TiO}_{2}$.
Furthermore, the mesoporous sample containing AuNPs was capable of visible light-induced photobleaching of MB. The catalytic reaction only occurred upon irradiation with light of wavelengths that matched the SPR absorption peaks of AuNPs and MB (data not shown). Controlling the size and morphology of metal NPs contacting anatase $\mathrm{TiO}_{2}$ produced novel photocatalysts with wavelength selectivity because of their variable SPR properties.

\section{Summary}

Many techniques to prepare metal NPs of controlled shape, dimensions, and orientation using soft/hard templates have 


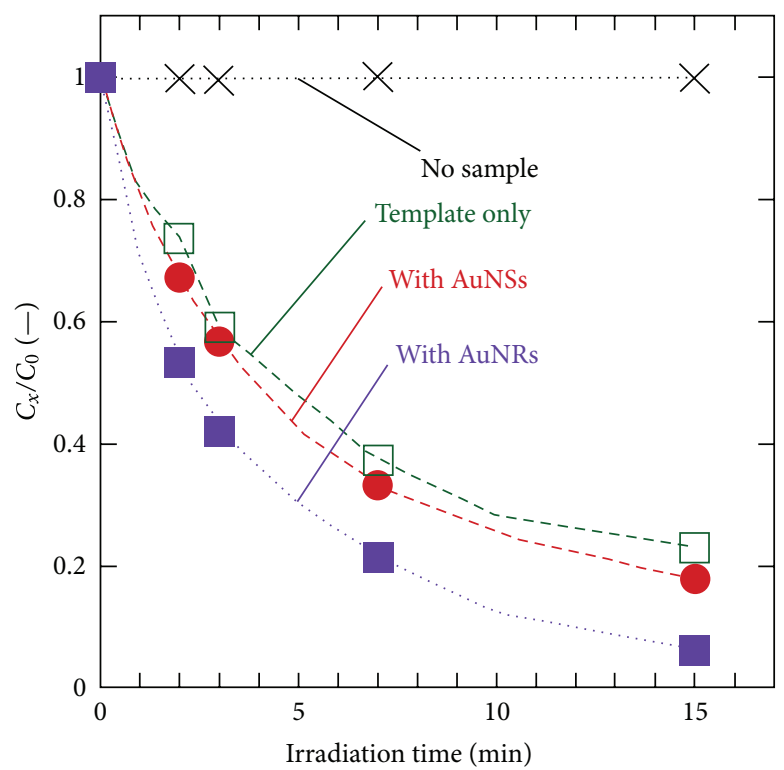

FIGURE 22: Photobleaching dynamics of MB solution with various samples upon UV irradiation. $C_{x}$ is the concentration of MB in the solution irradiated with UV light for a certain period, and $C_{0}$ is the initial concentration of $\mathrm{MB}$ in the solution.

been reported, allowing various nanostructures to be readily obtained. Extensive research has been performed on noble metal NPs, some of which have found application in recent years. However, it is difficult to control the morphology of many base metal nanostructures because they are easily oxidized. Once environmentally-friendly, inexpensive methods to prepare metal nanostructures, including those of base metals, are established, it is expected that the application of metal nanostructures will expand significantly.

\section{Acknowledgment}

This work was supported by JSPS KAKENHI Grant no. 22760539.

\section{References}

[1] G. Mie, "Contributions to the optics of turbid media, particularly of colloidal metal solutions," Annals of Physics, vol. 25, no. 3, pp. 377-445, 1908.

[2] J. M. Pitarke, V. M. Silkin, E. V. Chulkov, and P. M. Echenique, "Theory of surface plasmons and surface-plasmon polaritons," Reports on Progress in Physics, vol. 70, no. 1, pp. 1-87, 2007.

[3] P. M. Paulus, A. Goossens, R. C. Thiel, A. M. van der Kraan, G. Schmid, and L. J. de Jongh, "Surface and quantum-size effects in Pt and Au nanoparticles probed by ${ }^{197} \mathrm{Au}$ Mossbauer spectroscopy," Physical Review B, vol. 64, no. 20, Article ID 205418, 18 pages, 2001.

[4] M.-C. Daniel and D. Astruc, "Gold nanoparticles: assembly, supramolecular chemistry, quantum-size-related properties, and applications toward biology, catalysis, and nanotechnology," Chemical Reviews, vol. 104, no. 1, pp. 293-346, 2004.

[5] A. A. Ismail and D. W. Bahnemann, "Mesostructured pt/tio nanocomposites as highly active photocatalysts for the photooxidation of dichloroacetic acid," Journal of Physical Chemistry C, vol. 115, no. 13, pp. 5784-5791, 2011.
[6] L. Vigderma, B. P. Khanal, and E. R. Zubarev, "Functional gold nanorods: synthesis, self-assembly, and sensing applications," Advanced Materials, vol. 24, pp. 4811-4841, 2012.

[7] S. Y. Li and M. Wang, "Branched metal nanoparticles: a review on wet-chemical synthesis and biomedical applications," Nano LIFE, vol. 2, no. 1, Article ID 123000, 22 pages, 2012.

[8] I. Lisiecki, "Size, shape, and structural control of metallic nanocrystals," Journal of Physical Chemistry B, vol. 109, no. 25, pp. 12231-12244, 2005.

[9] C. Raab, M. Simko, U. Fiedeler, M. Nentwich, and A. Gazso, "Production of nanoparticles and nanomaterials," NanoTrust Dossiers, no. 6, pp. 1-4, 2011.

[10] J. Eastoe, M. J. Hollamby, and L. Hudson, "Recent advances in nanoparticle synthesis with reversed micelles," Advances in Colloid and Interface Science, vol. 128-130, pp. 5-15, 2006.

[11] E. K. Heidari, E. Marzbanrad, C. Zamani, and B. Raissi, "Nanocasting synthesis of ultrafine $\mathrm{WO}_{3}$ nanoparticles for gas sensing applications," Nanoscale Research Letters, vol. 5, no. 2, pp. 370-373, 2009.

[12] A. Otto, I. Mrozek, H. Grabhorn, and W. Akemann, "Surfaceenhanced Raman scattering," Journal of Physics, vol. 4, no. 5, pp. 1143-1212, 1992.

[13] B. Sharma, R. R. Frontiera, A.-I. Henry, E. Ringe, and R. P. Van Duyne, "SERS: materials, applications, and the future," Materials Today, vol. 15, no. 1-2, pp. 16-25, 2012.

[14] T. Yanagisawa, T. Shimizu, K. Kuroda, and C. Kato, "The preparation of alkyltrimethylammonium-kanemite complexes and their conversion to microporous materials," Bulletin of the Chemical Society of Japan, vol. 63, no. 4, pp. 988-992, 1990.

[15] C. T. Kresge, M. E. Leonowicz, W. J. Roth, J. C. Vartuli, and J. S. Beck, "Ordered mesoporous molecular sieves synthesized by a liquid-crystal template mechanism," Nature, vol. 359, no. 6397, pp. 710-712, 1992.

[16] A. M. James and M. P. Lord, Macmillan's Chemical and Physical Data, Macmillan, London, UK, 1992. 
[17] J. E. Huheey, E. A. Keiter, and R. L. Keiter, Inorganic Chemistry: Principles of Structure and Reactivity, HarperCollins, New York, NY, USA, 4th edition, 1993.

[18] S. Mandal, S. K. Arumugam, S. D. Adyanthaya, R. Pasricha, and M. Sastry, "Use of aqueous foams for the synthesis of gold nanoparticles of variable morphology," Journal of Materials Chemistry, vol. 14, no. 1, pp. 43-47, 2004.

[19] C. J. Murphy, T. K. Sau, A. M. Gole et al., "Anisotropic metal nanoparticles: synthesis, assembly, and optical applications," Journal of Physical Chemistry B, vol. 109, no. 29, pp. 13857-13870, 2005.

[20] G. C. Schatz, M. A. Young, and R. P. Van Duyne, "Electromagnetic mechanism of SERS," in Surface Enhanced Raman Scattering Physics and Applications, K. Kneipp, M. Moskovits, and H. Kneipp, Eds., vol. 103 of Topics in Applied Physics, pp. 19-46, New York, NY, USA, 2006.

[21] G. Kawamura and M. Nogami, "Application of a conproportionation reaction to a synthesis of shape-controlled gold nanoparticles," Journal of Crystal Growth, vol. 311, no. 19, pp. 4462-4466, 2009.

[22] P. Mulvaney, M. Giersig, and A. Henglein, "Electrochemistry of multilayer colloids: preparation and absorption spectrum of gold-coated silver particles," Journal of Physical Chemistry, vol. 97, no. 27, pp. 7061-7064, 1993.

[23] A. Henglein and M. Giersig, "Radiolytic formation of colloidal tin and tin-gold particles in aqueous solution," Journal of Physical Chemistry, vol. 98, no. 28, pp. 6931-6935, 1994.

[24] G. Kawamura, Y. Yang, K. Fukuda, and M. Nogami, "Shape control synthesis of multi-branched gold nanoparticles," $M a$ terials Chemistry and Physics, vol. 115, no. 1, pp. 229-234, 2009.

[25] C. J. Johnson, E. Dujardin, S. A. Davis, C. J. Murphy, and S. Mann, "Growth and form of gold nanorods prepared by seedmediated, surfactant-directed synthesis," Journal of Materials Chemistry, vol. 12, no. 6, pp. 1765-1770, 2002.

[26] P. L. Gai and M. A. Harmer, "Surface atomic defect structures and growth of gold nanorods," Nano Letters, vol. 2, no. 7, pp. 771-774, 2002.

[27] S. Chen, Z. L. Wang, J. Ballato, S. H. Foulger, and D. L. Carroll, "Monopod, bipod, tripod, and tetrapod gold nanocrystals," Journal of the American Chemical Society, vol. 125, no. 52, pp. 16186-16187, 2003.

[28] J. L. Burt, J. L. Elechiguerra, J. Reyes-Gasga, J. M. MontejanoCarrizales, and M. Jose-Yacaman, "Beyond Archimedean solids: star polyhedral gold nanocrystals," Journal of Crystal Growth, vol. 285, no. 4, pp. 681-691, 2005.

[29] O. M. Bakr, B. H. Wunsch, and F. Stellacci, "High-yield synthesis of multi-branched urchin-like gold nanoparticles," Chemistry of Materials, vol. 18, no. 14, pp. 3297-3301, 2006.

[30] C. L. Nehl, H. Liao, and J. H. Hafner, "Optical properties of star-shaped gold nanoparticles," Nano Letters, vol. 6, no. 4, pp. 683-688, 2006.

[31] D. Wang, Y. Liu, X. Zhou, J. Sun, and T. You, "EDTA-controlled one-pot preparation of novel shaped gold microcrystals and their application in surface-enhanced raman scattering," Chemistry Letters, vol. 36, no. 7, pp. 924-925, 2007.

[32] E. Herrero, L. J. Buller, and H. D. Abruña, "Underpotential deposition at single crystal surfaces of $\mathrm{Au}, \mathrm{Pt}, \mathrm{Ag}$ and other materials," Chemical Reviews, vol. 101, no. 7, pp. 1897-1930, 2001.

[33] M. Liu and P. Guyot-Sionnest, "Mechanism of silver(I)-assisted growth of gold nanorods and bipyramids," Journal of Physical Chemistry B, vol. 109, no. 47, pp. 22192-22200, 2005.
[34] M. Törnblom and U. Henriksson, "Effect of solubilization of aliphatic hydrocarbons on size and shape of rodlike $\mathrm{C}_{16} \mathrm{TABr}$ micelles studied by ${ }^{2} \mathrm{H}$ NMR relaxation," Journal of Physical Chemistry B, vol. 101, no. 31, pp. 6028-6035, 1997.

[35] Y. Y. Yu, S. S. Chang, C. L. Lee, and C. R. C. Wang, "Gold nanorods: electrochemical synthesis and optical properties," Journal of Physical Chemistry B, vol. 101, no. 34, pp. 6661-6664, 1997.

[36] S. S. Chang, C. W. Shih, C. D. Chen, W. C. Lai, and C. R. C. Wang, "The shape transition of gold nanorods," Langmuir, vol. 15, no. 3, pp. 701-709, 1999.

[37] N. R. Jana, L. Gearheart, and C. J. Murphy, "Seed-mediated growth approach for shape-controlled synthesis of spheroidal and rod-like gold nanoparticles using a surfactant template," Advanced Materials, vol. 13, no. 18, pp. 1389-1393, 2001.

[38] G. Kawamura, Y. Yang, and M. Nogami, "Facile assembling of gold nanorods with large aspect ratio and their surfaceenhanced Raman scattering properties," Applied Physics Letters, vol. 90, no. 26, Article ID 261908, 3 pages, 2007.

[39] G. Kawamura, Y. Yang, and M. Nogami, "End-to-end assembly of CTAB-stabilized gold nanorods by citrate anions," Journal of Physical Chemistry C, vol. 112, no. 29, pp. 10632-10636, 2008.

[40] J. Aizpurua, G. W. Bryant, L. J. Richter, and F. J. Garcia de Abajo, "Optical properties of coupled metallic nanorods for field-enhanced spectroscopy," Physical Review B, vol. 71, no. 23, Article ID 235420, 13 pages, 2005.

[41] J. Pérez-Juste, I. Pastoriza-Santos, L. M. Liz-Marzán, and P. Mulvaney, "Gold nanorods: synthesis, characterization and applications," Coordination Chemistry Reviews, vol. 249, no. 1718, pp. 1870-1901, 2005.

[42] N. R. Jana, L. Gearheart, and C. J. Murphy, "Wet chemical synthesis of high aspect ratio cylindrical gold nanorods," Journal of Physical Chemistry B, vol. 105, no. 19, pp. 4065-4067, 2001.

[43] D. Frenkel, H. N. W. Lekkerkerker, and A. Stroobants, “Thermodynamic stability of a smectic phase in a system of hard rods," Nature, vol. 332, no. 6167, pp. 822-823, 1988.

[44] J.-C. P. Gabriel and P. Davidson, "New trends in colloidal liquid crystals based on mineral moieties," Advanced Materials, vol. 12, no. 1, pp. 9-20, 2000.

[45] B. Nikoobakht, Z. L. Wang, and M. A. El-Sayed, "Self-assembly of gold nanorods," Journal of Physical Chemistry B, vol. 104, no. 36, pp. 8635-8640, 2000.

[46] S. Kwan, F. Kim, J. Akana, and P. Yang, "Synthesis and assembly of $\mathrm{BaWO}_{4}$ nanorods," Chemical Communications, no. 5, pp. 447-448, 2001.

[47] C. J. Orendorff and C. J. Murphy, "Quantitation of metal content in the silver-assisted growth of gold nanorods," Journal of Physical Chemistry B, vol. 110, no. 9, pp. 3990-3994, 2006.

[48] M. Gluodenis and C. A. Foss Jr., "The effect of mutual orientation on the spectra of metal nanoparticle rod-rod and rodsphere pairs," Journal of Physical Chemistry B, vol. 106, no. 37, pp. 9484-9489, 2002.

[49] Q. Jiang, H. M. Lu, and M. Zhao, "Modelling of surface energies of elemental crystals," Journal of Physics, vol. 16, no. 4, pp. 521-530, 2004.

[50] N. R. Jana, L. Gearheart, and C. J. Murphy, "Wet chemical synthesis of high aspect ratio cylindrical gold nanorods," Journal of Physical Chemistry B, vol. 105, no. 19, pp. 4065-4067, 2001.

[51] J. Aizpurua, G. W. Bryant, L. I. Richter, and F. J. Garcia de Abajo, "Optical properties of coupled metallic nanorods for field-enhanced spectroscopy," Physical Review B, vol. 71, no. 23, Article ID 235420, 13 pages, 2005. 
[52] Y. Dirix, C. Bastiaansen, W. Cased, and P. Smith, "Oriented pearl-necklace arrays of metallic nanoparticles in polymers: a new route toward polarization-dependent color filters," Advanced Materials, vol. 11, no. 3, pp. 223-227, 1999.

[53] J. Perez-Juste, B. Rodriguez-Gonzalez, P. Mulvaney, and L. M. Liz-Marzan, "Optical control and patterning of gold-nanorodpoly(vinyl alcohol) nanocomposite films," Advanced Functional Materials, vol. 15, no. 7, pp. 1065-1071, 2005.

[54] C. J. Murphy and C. J. Orendorff, "Alignment of gold nanorods in polymer composites and on polymer surfaces," Advanced Materials, vol. 17, no. 18, pp. 2173-2177, 2005.

[55] T. Sawitowski, Y. Miquel, A. Heilmann, and G. Schmid, “Optical properties of quasi one-dimensional chains of gold nanoparticles," Advanced Functional Materials, vol. 11, no. 6, pp. 435-440, 2001.

[56] I. Bannat, K. Wessels, T. Oekermann, J. Rathousky, D. Bahnemann, and M. Wark, "Improving the photocatalytic performance of mesoporous titania films by modification with gold nanostructures," Chemistry of Materials, vol. 21, no. 8, pp. 1645-1653, 2009.

[57] G. Kawamura, I. Hayashi, H. Muto, and A. Matsuda, "Anisotropically assembled gold nanoparticles prepared using unidirectionally aligned mesochannels of silica film," Scripta Materialia, vol. 66, no. 7, pp. 479-482, 2012.

[58] H. Miyata and K. Kuroda, "Formation of a continuous mesoporous silica film with fully aligned mesochannels on a glass substrate," Chemistry of Materials, vol. 12, no. 1, pp. 49-54, 2000.

[59] T. Suzuki, Y. Kanno, Y. Morioka, and K. Kuroda, "Facile unidirectional alignment of mesochannels in a mesoporous silica film on a freshly cleaved mica surface," Chemical Communications, no. 28, pp. 3284-3286, 2008.

[60] W. Caseri, "Nanocomposites of polymers and metals or semiconductors: historical background and optical properties," Macromolecular Rapid Communications, vol. 21, no. 11, pp. 705-722, 2000.

[61] H. Nakashima, K. Furukawa, Y. Kashimura, and K. Torimitsu, "Self-assembly of gold nanorods induced by intermolecular interactions of surface-anchored lipids," Langmuir, vol. 24, no. 11, pp. 5654-5658, 2008.

[62] G. Kawamura, M. Murakami, T. Okuno, H. Muto, and A. Matsuda, "Length control of $\mathrm{Ag}$ nanorods in mesoporous $\mathrm{SiO}_{2}$ $\mathrm{TiO}_{2}$ by light irradiation," RSC Advances, vol. 1, no. 4, pp. 584-587, 2011.

[63] Y. Xie, S. Quinlivan, and T. Asefa, "Tuning metal nanostructures in mesoporous silica by a simple change of metal complexes and by reduction with grafted imines and hemiaminals," Journal of Physical Chemistry C, vol. 112, no. 27, pp. 9996-10003, 2008.

[64] Z. Li, C. Kübel, V. I. Pârvulescu, and R. Richards, "Size tunable gold nanorods evenly distributed in the channels of mesoporous silica," ACS Nano, vol. 2, no. 6, pp. 1205-1212, 2008.

[65] Y. Ohko, T. Tatsuma, T. Fujii et al., "Multicolour photochromism of $\mathrm{TiO}_{2}$ films loaded with silver nanoparticles," Nature Materials, vol. 2, no. 1, pp. 29-31, 2003.

[66] G. Kawamura, T. Okuno, H. Muto, and A. Matsuda, "Selective preparation of zero- and one-dimensional gold nanostructures in a $\mathrm{TiO}_{2}$ nanocrystal-containing photoactive mesoporous template," Nanoscale Research Letters, vol. 7, no. 1, p. 27, 2012.
[67] E. Kowalska, O. O. P. Mahaney, R. Abe, and B. Ohtani, "Visiblelight-induced photocatalysis through surface plasmon excitation of gold on titania surfaces," Physical Chemistry Chemical Physics, vol. 12, no. 10, pp. 2344-2355, 2010. 

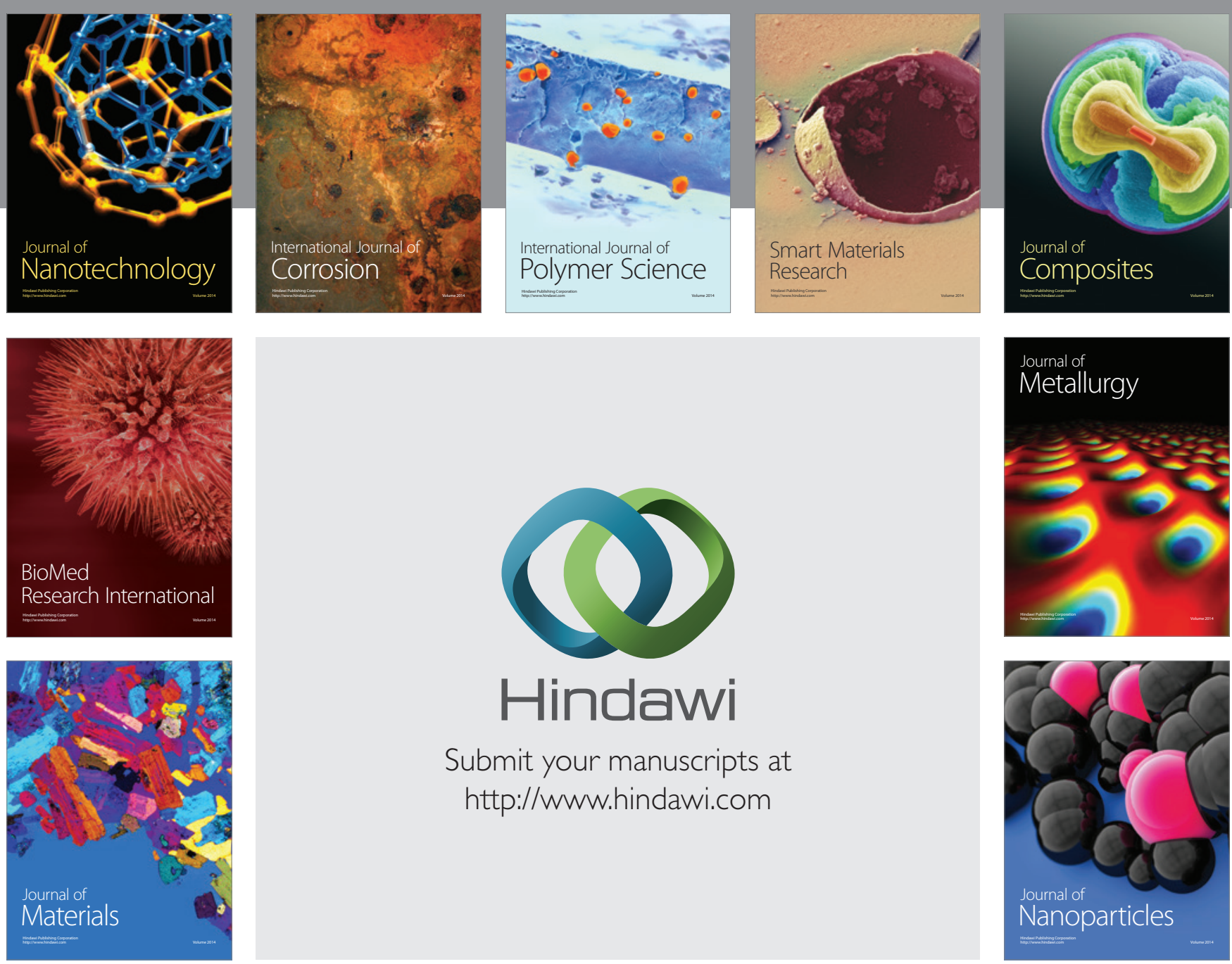

Submit your manuscripts at http://www.hindawi.com
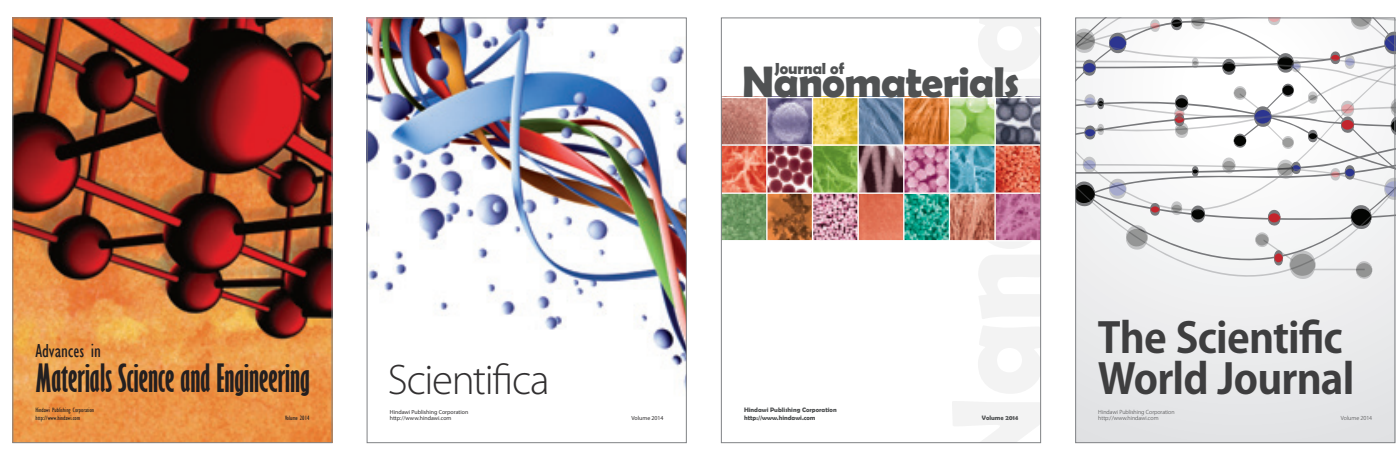

\section{The Scientific World Journal}
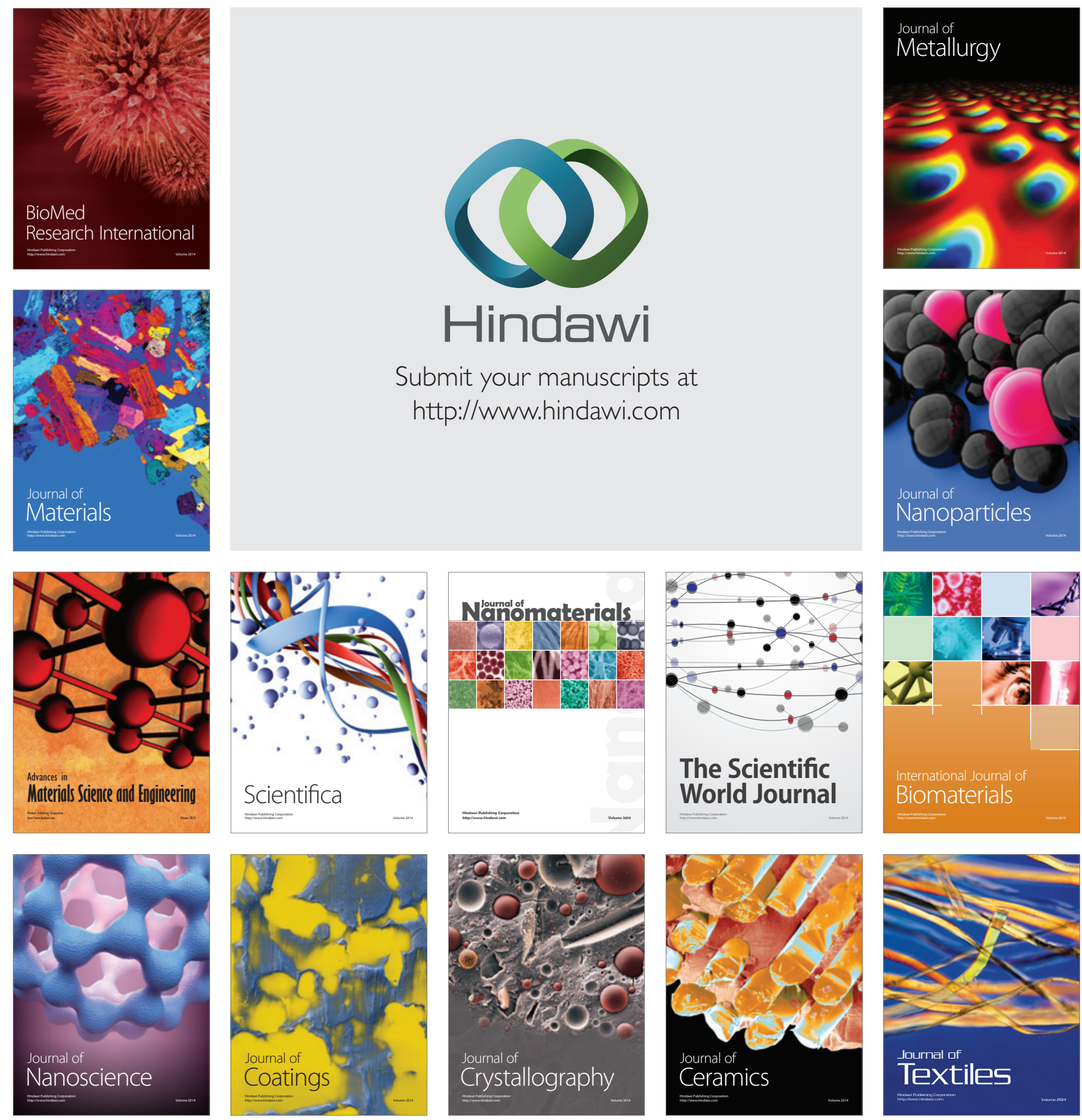